\title{
Reproduction of Social Inequality through Housing: \\ A Three-Generational Study from Norway
}

\author{
George Galster \\ Department of Urban Studies and Planning \\ Wayne State University \\ Detroit, MI 48202, USA \\ Email: george.galster@wayne.edu
}

\section{Terje Wessel}

Department of Sociology and Human Geography

University of Oslo

0316 Oslo, Norway

Email: terje.wessel@sosgeo.uio.no

The authors thank Lena Magnusson Turner, Viggo Nordvik and three anonymous referees for their helpful comments on an earlier draft. 


\begin{abstract}
The means through which socioeconomic status is transmitted across generations has long been of central interest to scholarship on inequality. We explore multi-generational reproduction of socioeconomic status through transmission of housing wealth by investigating how the tenure, size and location of housing occupied by grandparents relates to the tenure and value of housing occupied by their grandchildren. We estimate OLS, tobit and structural equation models based on Norwegian register data on three generations of families linked from 1960 to 2015. We find that those whose grandparents owned a large home in Oslo in 1960 had a much higher probability of owning a home in 2014, and among owners their dwellings were valued substantially more, compared to otherwise similar individuals whose grandparents were renters not living in cities. A natural experiment of housing price deregulation in Oslo indicates that resource transfers, not socialization of housing-related norms, was the dominant mechanism behind this process. Influences on parents' and grandchildren's income and education are substantial mediators. Results document the crucial role played by housing wealth in perpetuating social inequalities across several generations.
\end{abstract}

Key Words: homeownership, housing wealth, intergenerational bequests, socioeconomic inequality, intergenerational inequality, housing appreciation, structural equation models Abstract Word Count: 179 Paper word count: 12,659 incl. references \& notes, plus 5 tables, 1 figure, 2 appendix tables. 


\section{Introduction}

There are three themes in social stratification scholarship relevant for this paper. The first involves understanding the intergenerational transmission of socioeconomic status, primarily as measured by education and occupational status. Numerous statistical models have quantified how strongly peoples' achieved status reflected the occupational prestige and educational attainment of their parents, beginning with the seminal works of Blau and Duncan (1967) and Jencks et al. (1972). Some of the earliest thinking about the mechanism underlying these relationships suggested that parents instill particular values, norms and aspirations associated with their own education and occupation that lead to predictable consequences in the child's own educational and labor market experiences (e.g., Duncan, Featherman and Duncan, 1972). Subsequent scholarship supplemented this view of causal mechanisms by considering the independent role played by parental income and wealth (e.g., Haveman and Wolfe, 1994; Mayer, 1997; Spilerman, 2000). In this more robust framing, parental financial resources can benefit their offspring in a variety of ways, both directly and indirectly. Directly, parents can bestow financial gifts (both before and after they die) that supplement the wealth of their children, permitting greater consumption during their lifetimes. Even before being transferred, parental wealth may serve as a familial "safety net" for their offspring, and lead them to undertake more risks and indebtedness. Indirectly, parents can employ their assets to invest in the human capital (and future incomes) for their children, spending more on housing so they can attend a higherquality public school district, paying tuition for a private school, hiring tutors, financing extracurricular enrichment activities, investing in their entrepreneurial endeavors, etc. These and other aspects of intergenerational financial transfers have been explored theoretically by scholars from several social sciences, e.g., Cox (1990), Engelhardt and Mayer (1998), Lindh and Ohlsson (1998), Boehm and Schlottmann (2002), Guiso and Japelli (2002), Torche and Spilerman (2006), and Shapiro, Meschede, and Osoro (2013).

The second theme of relevance here is the emergence of owning one's home as an important indicator of achieved status, beyond education and occupation. Prominence of this indicator is understandable for several reasons. First, in the U.S. and Western Europe it represents the dominant element of the wealth portfolio for the vast majority of households (Hamnett et al., 1991, Chapter 3; Arrondel and Lefebvre, 2001; Flavin and Yamashita, 2002; 
Orzechowski and Sepielli, 2003; Brandolini et al., 2006; Nordvik and Åhrén, 2016) and over the long term has served as a major vehicle for wealth accumulation (Boehm and Schlottman, 2004; Belsky and Prakken, 2004). Second, its price volatility, spatial fixity and vulnerability to a wide range of tax, environmental and housing market public policies make it an unusual form of asset (Rothenberg, et al., 1991). Third, homeownership may convey a range of positive externalities for the larger society, ranging from enhanced maintenance of dwellings, citizen participation and children's well-being (Rohe, Van Zandt and McCarthy, 2013). Fourth, owning a home may have important effects on the geographic mobility of individuals, such as when they have an outstanding mortgage balance in excess of the home's market value. Finally, and perhaps of greatest relevance here, given the common empirical finding across many national contexts of a strong correlation in home ownership between parents and their adult children (Jenkins and Maynard, 1983; Henretta, 1984; Mulder and Wagner, 1998; Engelhardt and Mayer, 1998; Mulder and Smits, 1999; Boehm and Schlottmann, 1999; Semyonov and Lewin-Epstein, 2001; Kurz, 2004; Helderman and Mulder, 2007; Poggio, 2008; Aratani, 2011; Enström Öst, 2012; Mulder and Smits, 2013; Barrett et al., 2015; Mulder et al., 2015), homeownership appears to be a major vehicle by which wealth is transferred across generations (Boehm and Schlottmann, 2002; Kurz and Blossfeld, 2004; Maclennan and Miao, 2017).

Of course, the ownership of real property is insufficient to deduce that its value will grow substantially, let alone be preserved over time or between generations. Clearly, timing and location of the original property purchase by the family are crucial (Boehm and Schlottmann, 2002, 2004). This latter aspect connects with a third body of scholarship relevant to our paper that focuses on the spatial foundations of social inequality (Wilson, 1987; Jencks and Mayer, 1990; Galster and Killen, 1995; Briggs, 1995; Brooks-Gunn, Duncan and Aber, 1997. This work contends that over the last few decades there has been a notable growth of geographic inequalities in socioeconomic, environmental, institutional and political domains that both reflect and, more importantly from the perspective of this paper, contribute to these inequalities across individuals and generations (Sharkey, 2016; Galster and Sharkey, 2017). Emblematic of recent empirical research in this realm, Lindley and Machin (2014) found that U.S. metropolitan areas with higher shares of college-educated workers in 1980 experienced greater employment growth and demand for high-paid workers from 1980 to 2010, leading to burgeoning inequality across metropolitan areas. Chetty et al. (2014) identified substantial variation in intergenerational 
mobility between income classes across U.S. counties and regions, and subsequent research strongly suggested that places themselves have causal effects on the probability of upward mobility (Chetty and Hendren, 2015). Unfortunately, less progress has been made in identifying the specific characteristics of places that facilitate or impede upward mobility and the intergenerational transmission of inequality (Galster and Sharkey, 2017). We believe that one of those key characteristics is inflation in the local housing market.

Our research bridges these three strands of multi-disciplinary, social scientific enquiry by investigating the degree to which both the ownership of real property and its location in a rapidly inflating market significantly contributes to the transmission of social inequality among not only two but three generations of families. Our extension of the analysis across three generations is warranted for several reasons. First, intergenerational persistence of wealth inequality will be enhanced if grandparents directly transfer wealth to grandchildren, instead of only doing so indirectly via the intervening effects on parents. Second, direct transfers of wealth from grandparents likely occur at more formative (i.e., young adult) stages in the life course of children than do transfers from parents. Third, given the increasing life spans of grandparents, the growing overlap between their lives and their grandchildren's magnifies the opportunities for many intergenerational influences to be transmitted. Fourth, cross-grandparental variance in housing wealth will be intensified compared to such variance across parents, to the degree that interregional variations in housing price inflation have grown over time. Finally, failure to consider the role of grandparental wealth may lead to erroneous conclusions about the intergenerational transmission of wealth between parents and children (Mare, 2011).

Specifically, in bridging these literatures our paper addresses the following research questions:

1. Is the ownership of real property by grandparents strongly related to the housing wealth held by their young adult grandchildren?

2. To what degree is this relationship influenced by the geographical location in which the grandparents' property is located?

3. To what degree is this relationship mediated by influences transmitted through the parents'socioeconomic status? 


\section{To what degree is this relationship associated with the intergenerational transmission of} financial resources, instead of values and norms, related to homeownership?

We investigate these questions in Norway, a country that combines egalitarian policies and a strong public sector with a cultural affinity for homeownership. Recent measurements place Norway at the very top of the "welfare state generosity index" (Scruggs et al., 2014), and a high rank on public spending statistics (OECD, 2016). The privileged status of owner-occupancy in social norms and public policy in Norway dates back seventy years, and has become a selfevident feature of the political landscape. Few have suggested that Norway should switch to a tenure-neutral housing policy, even though homeownership now constitutes 84 percent of the housing stock (Statistics Norway, 2017a). Some, however, have started to worry about the implications of the burgeoning investments and returns in the housing sector (Røed Larsen and Weum, 2008; Nordvik and Åhrén, 2016) and the associated accumulation of wealth, particularly in Oslo, but also to some degree in other cities.

These worries have become especially acute given a context in which Norway's evolving urban economy and more neo-liberal public policies have contributed to increased prosperity concentrated at the upper end of the social hierarchy (Aaberge and Atkinson, 2010; Wessel, 2013; Hansen, 2014). In particular, there are concerns that geographic variations in housing market performance are creating better opportunities for some groups to invest in building their human capital and migrate to areas with enhanced economic prospects. Those who are potentially most favored by this phenomenon are seen to be those who descend from Oslo families who have owned homes for long periods and multiple generations (and thus hold sizable home equity), given that Oslo has experienced the fastest increase in house prices in Norway over the last three decades. House prices in Oslo grew 353 percent over the period 1982 to 2014 (CPI-adjusted), compared to 287 percent for Norway as a whole (Norges Bank, 2017). ${ }^{1}$ By contrast, the least-favored appear to be those who descend from homeowners living in the countryside or from tenants.

The distinguishing feature of this perspective is not simply homeownership per se (which is dominant in Norway), but also the ability to build home equity. It is comparably easy for

\footnotetext{
${ }^{1}$ We chose 1982 as baseline because many housing market regulations, including price ceilings, disappeared from this year onwards in Norway.
} 
young adults to access homeownership in peripheral regions of Norway, but the status as homeowner there will often come at the cost of low or even negative house price appreciation. It may thus be difficult, if not impossible, to convert such minimal property wealth into buying a decent home in a larger city. Even those emigrants from peripheral areas who leave for the city at a young age (e.g., to attend college) face difficult competition for purchasing housing, since local peers may be able to draw on a larger stock of housing-based wealth accumulated by prior generations. We therefore employ both the purchasing of a home and the value of that home as the primary outcome variables of interest in this study. Owning a higher-valued home captures not only a major component of wealth and achieved status, but also the degree to which people can feasibly choose a higher-priced location at which to reside, whether they want to move from one region to another or relocate within the current region.

Our analyses of homeownership and home values of young adult Norwegians (ages 25 to 44) are notable in three ways: (1) data covering three generations that span more than 50 years; (2) rich controls; (3) a natural experiment. We use a combination of 1960 and 1990 census data and population register data, utilizing links in the multigenerational register that allow us to merge information across children, parents and grandparents for the 1960 to 2015 period. Our primary explanatory factor of interest is grandparents' housing market position in 1960, delineated according to tenure (rental vs. owner-occupied), house size (number of rooms) and location (Oslo, other cities, less-urbanized areas). Important intervening variables include income, wealth, education and demographic characteristics, measured across the three generations. We estimate structural equation models in an effort to measure the direct and indirect effects of housing wealth of prior generations on the younger generation's housing prospects. Finally, we exploit a natural experiment involving a public policy that deregulated housing prices in one segment of the ownership sector to gain insights into the mechanisms that link Oslo grandparents' historical housing market position to the current value of homes owned by young adults. In brief, we find that the randomness of family history plays a non-trivial role in the housing market outcomes of the current generation; the good fortune of having a grandparent owning a large home in Oslo indeed provides a good fortune. 


\section{Theoretical and empirical background}

\subsection{Causal mechanisms}

The mechanisms that lie behind intergenerational transmission of housing tenure and property wealth are multiple and complex, and may involve a combination of deliberate actions, normative behavior and coinciding circumstances. To our knowledge, no one has developed a model for such transmissions across three generations. In doing so we synthesize and extend theoretical arguments made in the context of the well-developed literature on housing status transmissions across two generations.

It is, as a start, important to acknowledge that relevant influences may be direct, from grandparents to grandchildren, and/or mediated, from grandparents to parents and further to grandchildren. Following Mare (2011: 7), we therefore perceive the causal chain as a matter of legacy: the characteristics of grandparents (generation 1 hereafter) and parents (generation 2) affect the characteristics of young adult grandchildren (generation 3), with generation 1 also affecting generation 2 in ways that potentially give rise to mediated effects. A visual representation of our conceptual model for the multi-generational transmission of housing tenure and wealth, showing both direct and mediated causal paths between generations 1 and 3 , is portrayed in Figure 1. Underlying these paths are four agents through which one generation's housing wealth might potentially influence that held by the succeeding one: inheritance, gifting, socialization and developmental context.

[Figure 1. about here]

The first causal agent is inheritance of real property. What recipients will do with this largess is uncertain. One solution is to adopt a life-cycle accumulation strategy, e.g., by moving into the homes bequeathed to them, perhaps thereby becoming "instant homeowners" if they had not owned previously (see path D in Figure 1). We also note that inheritance may affect housing investments through anticipation; some households appear to incur debt as an adjustment to expected future inheritance (Gulbrandsen and Langsether, 2003). Inheritors may instead choose to rent out bequeathed homes or sell them, thereby augmenting their income and wealth and their concomitant financial ability to buy their first dwellings or more expensive ones (see paths $\mathrm{H}$ E). Which of these aforementioned options is chosen is likely to vary with institutional, geographic and temporal context: inheritance taxation (Pfeffer, 2014), tax treatment of housing- 
related capital gains, depreciation and rental income, housing policies and housing market price and vacancy conditions (Spilerman, 2000).

The second causal agent is inter-generational transfers of gifts of assets, information and other resources transmitted inter vivos, i.e., while both parties are still alive (see paths H - E). An older generation may borrow against their home equity to provide financial gifts that help in overcoming mortgage downpayment constraints of the younger generation (Cox, 1990; Engelhardt and Mayer, 1998; Guiso and Jappelli, 2002). ${ }^{2}$ Homeowners of an earlier generation may also provide collateral (by co-signing mortgage notes), reputation of credit-worthiness, information about how to shop more effectively for the best mortgage products, and other sorts of information based on their home-owning experience that could plausibly affect the opportunities of the next generation to buy a home (Mulder and Smits, 1999; Helderman and Mulder, 2007; Spilerman and Wolff, 2012).

A third causal agent is transmission of values and attitudes towards homeownership. The "socialization thesis" suggests that children who are brought up in a homeownership context acquire aspirations and preferences for the same tenure (see paths $\mathrm{F}-\mathrm{A}$ ). This thesis has been frequently debated in the literature (Henretta, 1984; Mulder and Smits, 1999; Helderman and Mulder, 2007; Smits and Michielin, 2010; Mulder et al., 2015) but has recently found support in a two-generational study that covers 13 European countries (Lersch and Luijkx, 2015).

The last agent is developmental context. The housing wealth of an older generation may affect the recipient generations' housing opportunities indirectly by influencing the physical, social and institutional environment to which children and youth are exposed (see paths G - B E). Greater ancestral housing wealth enables the consumption of a healthier environmental context within the home and outside it, so that succeeding generations are more likely to develop more fully intellectually and behaviorally. It also may permit descendants to access superior public service packages (recreation, safety, schools and extra-school educational enrichment opportunities) and peer networks. In turn, all these felicitous consequences raise the likelihood that descendants will develop a superior set of skills and educational credentials (path G), which will payoff in the form of higher incomes and more wealth as an adult (path B). These status markers will drive obvious consequences for their eventual abilities to purchase (more

\footnotetext{
${ }^{2}$ A recent survey for the U.S. National Association of Realtors found that 26 percent of first-time homebuyers during 2001-2014 received gifts to make their down payments; cited in Lee et al., 2017)
} 
expensive) dwellings, as per path E (Smits and Michielin, 2010). There is a large body of scholarship that finds a link between parental homeownership and many of the child outcomes discussed above (Haurin, 1992; Haveman and Wolfe, 1994; Brooks-Gunn et al., 1997; Green and White, 1997; Mayer, 1997; Boehm and Schlottmann, 1999; Aaronson, 2000; Harkness and Newman, 2002; 2003; Haurin Parcel and Haurin, 2002; Dietz and Haurin, 2003; Galster et al., 2007; Green, Painter and White, 2012).

Thus far, we have considered four potential causal connections between two generations' housing statuses; here we consider nuances arising from a three-generation conceptualization such as ours. Housing wealth held by generation 1 might be transferred to generation 3 via bequests or transfers, thus assisting in home purchase directly (see path $\mathrm{C}$ in Figure 1) or indirectly via augmenting generation 3 wealth (path L). Another alternative is for generation 2 to pass on to generation 3 in analogous fashion housing wealth inherited from generation 1, now as gifts or later as inheritance (see paths $\mathrm{M}-\mathrm{D}$ and $\mathrm{M}-\mathrm{H}$ ). Direct socialization of homeownership values and beliefs between generations 1 and 3 (paths $\mathrm{J}-\mathrm{A}$ ) may be less likely without close daily contact; it more likely will be transmitted via generation 2 mediation (paths $\mathrm{I}-\mathrm{F}-\mathrm{A}$ ). Similarly, unless generation 3 children are being raised by generation 1, we deem it more typical that any developmental context effects from generations 1 to 3 are primarily mediated (via paths $\mathrm{I}-\mathrm{K}$ - etc.). The strength of all direct effects between generations 1 and 3 likely will be contingent on whether grandchildren have settled close to their grandparents, since proximity facilitates contact and support (Hodgson, 1992). This is new territory in social science research, with more speculation than firm evidence. It may be inferred, however, that one or more of these mechanisms connecting grandparents and grandchildren are potentially powerful, especially among wealthy families (Mare, 2011; Pfeffer, 2014; Hällsten and Pfeffer, 2017).

\subsection{Prior empirical work}

There is a substantial body of prior work spanning many countries that identifies strong correlations between parents' income, wealth, homeownership status and/or financial gifts to their children, and housing outcomes of their adult children. Higher children's homeownership rates have been associated with parental: homeownership (Boehm and Schlottman, 2002; Mulder and Smits, 1999, 2013); ${ }^{3}$ wealth (Charles and Hurst, 2002; Hilber and Liu, 2008; Öst, 2012;

\footnotetext{
${ }^{3}$ These patterns do not apply universally across all nations or socioeconomic groups; cf. Henretta (1984); Aratani (2011); Lee et al. (2017).
} 
Spilerman and Wolff, 2012; Bond and Eriksen, 2017) and intergenerational financial transfers (Mulder and Smits, 2013; Lee et al. 2017). Children owning a more expensive home has been associated with parental: income (Henretta, 1984; Smits and Michielin, 2010); wealth (Spilerman and Wolff, 2012); intergenerational transfers (Henretta, 1984; Engelhardt and Mayer, 1998; Guiso and Jappelli, 2002; Helderman and Mulder, 2007; Lee et al., 2017); and home value (Smits and Michielin, 2010).

This literature faces three main empirical challenges: reverse causation, spurious correlation and inability to disentangle mechanisms of causation. ${ }^{4}$ Reverse causation may arise if resources are transferred from younger to older generations, thus muddling the interpretation of any observed correlation (Albertini et al., 2007; Hällsten and Pfeffer, 2017).

Spurious correlation likely arises from two sources. First, young adults will often settle in the same region, or even in the same residential area, as their parents. Both generations are thus subjected to the same housing market conditions, which increases the inter-generational similarity in tenure and house value levels and changes, even if there are no direct causal connections between the generations (Smits and Michielin, 2010). The second source arises in the realm of the intergenerational transmission of social status, which may occur independent of the housing-related developmental context mechanism discussed above. Similarities in housing position across parents and children may merely reflect commonalities in aspirations, labor market position, skills, educational credentials etc., with no independent effect from parental homeownership or home equity (Helderman and Mulder, 2007; Kurz, 2004; Mulder et al., 2015). These potential spurious correlations can be reproduced across multiple generations, which underlines the importance of measurement over long time spans and extensive controls for multiple generations, such as we employ.

The final challenge is disentangling the welter of potential causal pathways, direct and indirect, possibly mediated, as portrayed in Figure 1. A core difficulty has been obtaining explicit measures of key variables operationalizing the different mechanisms. A few studies have been able to quantify intergenerational financial transfers (e.g., Henretta, 1984; Engelhardt and Mayer, 1998; Guiso and Jappelli, 2002; Helderman and Mulder, 2007; Mulder and Smits, 2013; Lee et al., 2017), but have been unable to relate them explicitly to parental housing tenure or

\footnotetext{
${ }^{4}$ For comprehensive discussions of the methodological challenges in this genre, see: Albertini et al. (2007); Aratani (2011); Spilerman and Wolff (2012); Lersch and Luijkx (2015); Hällsten and Pfeffer (2017).
} 
wealth sources. Lersch and Luijkx (2015) are unique in their analysis of a dataset that directly measures values related to homeownership, which offers convincing evidence that the socialization mechanism carries some explanatory power (although not to the exclusion of economic connections).

\subsection{Our contributions}

Our work makes five distinct contributions to the literature. First, the extension of the intergenerational transmission of housing status from two to three generations, and the long timespan over which we have measures, represents a novelty in this type of housing research. Second, our three-generational study reduces the risk of reverse causation: it is unlikely that grandparents' and grandchildren's housing assets are subject to endogeneity, given the timing of their respective housing careers. Third, to reduce dangers from spurious correlation we employ controls for co-residence of generations in the same locale and multiple controls for the socioeconomic status of generations 2 and 3. Fourth, we use structural equation modeling to assess the empirical contributions made by direct and mediated effects from grandparents on young adults' housing outcomes. ${ }^{5}$ Fifth, we leverage a natural experiment that allows us to disentangle whether the primary mechanism behind this multigenerational transmission process of housing status is economic or sociological in nature.

\section{Data and methods}

\subsection{Data Sources and Sample}

The data for our analyses are gathered from the Norwegian population and housing censuses of 1960 and 1990, plus several population registers under the control of Statistics Norway, the Norwegian Directorate of Taxes and the Norwegian Labor and Welfare Administration. ${ }^{6}$ We utilize links in the multigenerational register that allow us to merge information across children, parents and grandparents, spanning the period from 1960 to 2015.

The population we analyze includes individuals aged 25 to 44 years who lived in Norway on January 1, 2015. This age span is a trade-off between increased population coverage and

\footnotetext{
${ }^{5}$ Hällsten and Pfeffer (2017) use a fixed effect models as their primary analytical tool. They also test robustness, however, with a structural equation model: their dependent variable is grandchildren's wealth, with granparents' wealth as the key independent variable.

${ }^{6}$ The population and housing census of 1960 covers all households, whereas the census of 1990 was based on sampling in larger municipalities. The sampling rate varied according to the size of the municipality.
} 
temporal length of observation. We could not stretch the upper age-limit any further if we wanted to maintain a large analytic sample. ${ }^{7}$ At the other end, we did not want to exclude young adult cohorts, given the well-known association between family background and timing of first home purchase (Mulder and Wagner, 1998; Mulder and Smits, 1999; Guiso and Jappelli, 2002; Aratani, 2011; Enström Öst, 2012; Lee et al., 2017).

Our data set only contains individuals with Norwegian national background, including adopted children and children with a Norwegian-born mother or father. We exclude immigrants and their descendants for the simple reason that for most of them (around 99 percent) we lack information across three generations. We further require that both paternal and maternal family lines had at least one living grandparent in 1960 (else we had no information about them), and that all sampled young adults had left the family home at the end of 2014. As we will explain in section 3.3, we will categorize the housing status attained by the grandparents in both family lines as of 1960. In summary, the following figures apply for our sampling: the entire Norwegian population aged 25 to 44 on January 1, 2015 was 1,412,062; of which 1,053,478 individuals had Norwegian national background; of which 955,946 had left the family home; of which 690,255 had living grandparents on both family lines in 1960. We have further removed 28,457 individuals (4.1 percent) with lacking information on education (G1/G2), address (G3) and/or family type (G3), which reduces our final sample size to 661,798 .

\subsection{Dependent variables}

We analyze two dependent variables for our young adult sample: a binary measure for homeownership and a continuous measure for house value. Homeownership includes both individual and cooperative property, since these forms are subjected to similar market conditions. ${ }^{8}$ House value is estimated annually at Statistics Norway, and is based on a hedonic model that includes 797,000 sales over a 10-year period. Key variables behind the estimates are type of housing, residential space (square meters), housing age, region and price zone. Several reports (e.g., Haglund, 2017) document an acceptable correlation between observed and

\footnotetext{
${ }^{7}$ The share with living grandparents in 1960 drops rapidly for older cohorts. Obviously, the coverage is better for later censuses, but some technical details make these data less applicable. The 1970 census, for instance, does not distinguish between tenancy and co-operative homeownership.

${ }^{8}$ Quite many households in Norway invest in dwellings for rental purposes. In these cases, we only apply the value of the primary dwelling (i.e., the dwelling they live in), which is a conservative choice.
} 
estimated values, although with exceptions for thinly populated areas. ${ }^{9}$ All reports, and our own analyses, show significantly skewed distributions. We therefore use a log-transformed specification of house value (measured in Norwegian kroner, NOK).

\subsection{Key independent variables}

For our core analyses we employ a set of dummy variables that denote the housing status obtained by both the young adult's maternal and paternal grandparents as of 1960 . We obtain the requisite housing and settlement information from the 1960 census, which contains a large number of dwelling-related variables for the entire Norwegian population. Preliminary trials indicated that tenure, residential space and location were significant predictors of generation 3 house value, whereas type of housing proved less so. We tested several versions and combinations of these three key variables, ultimately settling upon 12 categories that describe grandparents' housing status in tripartite terms of tenure, location and size: 1) Rented in the rest of Norway, 2) Owned 1-3 rooms in the rest of Norway, 3) Owned 4 rooms in the rest of Norway, 4) Owned 5 + rooms in the rest of Norway, 5) Rented in tier-2 city, 6) Owned 1-3 rooms in tier-2 city, 7) Owned 4 rooms in tier-2 city, 8) Owned 5 + rooms in tier-2 city, 9) Rented in Oslo, 10) Owned 1-3 rooms in Oslo, 11) Owned 4 rooms in Oslo, 12) Owned 5 + rooms in Oslo. We used these dummy variables as proxies for the housing wealth held by generation 1, as there is no direct measure of such wealth available. Note that each observation of a young adult will have two dummy variables coded as "one," corresponding to both family lines.

Our designation of generation 1 housing status also takes into account that a small proportion of all grandparents (5 percent in 1960) were divorced, separated or otherwise living separately. In these cases, weassigned a dwelling to this familial line according to three principles: 1) owner-occupied dwellings were selected before rental dwellings, 2) owneroccupied dwellings were selected according to higher house value for the respective categories, and 3) rental dwellings were selected according to hierarchy of location/centrality, i.e., Oslo before tier-2 cities, and tier-2 cities before the rest of Norway.

Our application of 1990 census data is restricted to a natural experimental test of causal mechanisms among descendants from Oslo grandparents, which we explain below. The reasons why we select for this experiment only one city instead of the six largest ones, or the whole of

\footnotetext{
${ }^{9}$ The data have two purposes - they are used, firstly, as input in macroeconomic models at Statistics Norway, and, secondly, as a basis for taxation (wealth tax at the state level and property tax at the municipal level).
} 
Norway, are threefold. First, Oslo used to have one segment of its homeownership market strongly affected by price ceilings and similar regulatory restraints; the other segment was unregulated for most of the period. We may thus test whether the deregulatory market reforms of the mid-1980s have trickle-down effects on later generations. Second, the 1990 census varied in terms of sampling rate, response rate and data quality across different municipalities. These differences complicate aggregation at a subnational level for all places except Oslo. Third, the price ceiling regulations had a strong effect in Oslo: people had to sell their regulated dwellings far below the market price. Some of them could acquire part of the difference between regulated prices and market prices by selling in the black market, but quite many did not have this opportunity since the cooperative society handled all transactions (Gulbrandsen, 1983). By contrast, homeowners in the countryside and smaller cities were able to sell their dwellings in weaker markets with less housing inflation, which obviously reduced the financial impact of price ceilings upon them.

\subsection{Socioeconomic characteristics}

We apply two measures for education - one for generation 2, ranging from 1 (primary school) to 4 (master or $\mathrm{PhD}$ degree), and one for generation 3, ranging from 1 (primary school) to 8 ( $\mathrm{PhD}$ ). The reason for the difference in measurement is that all cohorts in generation 2 have only a fourlevel registration of education when the child (generation 3) reached 16 years of age, measured for the parent with the higher educational attainment.

Income for generation 1 and 2 is measured as personal income (wage and selfemployment income), using $1967^{10}$ for generation 1 and the average of 20 years for generation 2, starting the year after the sampled person in generation 3 was born. We adjust these measurements, both for generation 1 and generation 2, to the base 2014 NOK, using the consumer price index (CPI). Our measurement for generation 3 is net disposable income, measured in 2014 NOK.

Information regarding wealth is more sparse. Proper wealth registrations in Norway started in 1993, which implies that we cannot standardize across different cohorts of parents. Our solution is to use just one year, 1993, when a large part of generation 2 had reached midlife (average age: 38 years). The measure we employ is gross wealth, which includes estimated real

\footnotetext{
10 This time-gap should not be too problematic, since average age in 1967 was 43 years, and since few grandparents died between 1960 and 1967.
} 
property capital (both housing and commercial property) and taxable financial capital (cash, bank deposits, stocks, bonds, securities and private pension funds). Our wealth measure for generation 3 is taxable financial capital in 2014; their real property capital is the object of our investigation.

Our family aggregation rule for income and wealth is simple: we take the sum over parents and both lineages of grandparents. All these measures are logged to obtain more normal distribution.

\subsection{Demographic characteristics}

Both dependent variables may reflect a large number of demographic confounders. Our rich database allows us to control for: birth year for all three generations; number of siblings for generations 2 and 3; number of children for generation 3; civil status (couple/single) for generation 3; student status for generation 3; deaths for generation 1 (220 year dummies); and decades alive for generation 2 .

We further control for spatial proximity between generation 1 and 3 to avoid spurious correlation, given the importance of local housing market conditions. We employ a dummy variable that equals 1 if either family line of generation 1 resided in 1960 in the same municipality as generation 3 did in 2015. For this purpose, we had to merge 732 municipalities extant in 1960 into the 428 municipalities extant in 2015.

\subsection{Analytical strategy}

A challenge in our analysis is that education, income and wealth may affect housing outcomes in generation 3 either directly (i.e., as independent covariates) or through interaction with housing status exhibited by generations 1 and/or 2 (see Figure 1). We address this difficulty by using two sets of analyses. The first one involves linear regressions of the probability of generation 3 homeownership and log of house value among homeowners in generation 3, controlling for demographic and socioeconomic influences emanating from generations 2 and 3. We focus upon these models' results for the generation 1 housing categories specified above to answer our first two research questions: Is the ownership of real property by grandparents strongly related to the housing wealth held by their young adult grandchildren? To what degree is this relationship influenced by the geographical location in which the grandparents' property is located? The second set of analyses involves two structural equation models (standard path models), which 
provide an appropriate test of mediation effects that permit us to answer our third research question: To what degree is this relationship mediated by influences transmitted through the parents' socioeconomic status? We estimate the probability of homeownership as a function of all predictors in the conceptual framework (Figure 1), and repeat this analysis with house value as dependent variable, using a standard linear model (SEM) in both cases. We report three sets of outcomes: total effects, indirect effects via generation 2, and indirect effects via generations 2 and $3 .{ }^{11}$ Since all variables are observed, we only present one type of model statistics: the Akaike Information Criterion (AIC) (see Kenny, 2015). The improvements in these estimates correspond closely to the change in adjusted $\mathrm{R} 2$ in the regression models.

Finally, we explore long-term effects of Oslo housing market deregulatory reforms ${ }^{12}$ as a way to reveal potential mechanisms of intergenerational effects and thus answer our fourth research question: To what degree is this relationship associated with the intergenerational transmission of financial resources, instead of values and norms, related to homeownership? Our intuition behind this test is as follows. If norms and values related to homeownership were the prime mechanism driving the intergenerational transmission of housing status, we would expect that the mere fact of grandparents owning a home would have a similar impact on their grandchildren's housing status, regardless of the changes in these homes' equity values over time. Alternatively, if financial considerations were the primary driver, we would expect that grandchildren whose grandparents experienced more rapid appreciation in their properties would receive a stronger positive fillip to their housing status.

We test these predictions through use of the natural experiment that the prices of most small (i.e., less than four rooms) dwellings were regulated in Oslo until the deregulatory reforms of 1982-1985 less to their rapid appreciation, whereas those of larger dwellings were not (Gulbrandsen, 1983). The overall intuition of our test is as follows. If housing values or norms were the dominant mechanism of intergenerational transmission, it would not matter for one's

\footnotetext{
${ }^{11}$ All confounders except income in generation 1 are orthogonal to homeownership and log house value.

${ }^{12}$ Price regulations for owner-occupied property in Norway go back to 1940, and were lifted in 1969 (single-family homes) and over the period 1982-86 (the cooperative sector, including shareholder apartments). Cooperative dwellings were always tighter regulated than individual property, although with one exception: large cooperative dwellings and shareholder apartments were treated as individual property. Another complexity concerns the emergence of condominiums and "quasi-condominiums" in the 1970s. These dwellings escaped price regulation, and contributed to the growth of a black market in the regulated sector. Direct subsidies to detached housing complicate the picture further, but the major change in housing prices occurred as a direct effect of deregulation in 1982-86. For policy details, see Gulbrandsen (1983).
} 
own homeownership status whether one's grandparents owned a small or large home, or when (pre- or post-deregulation) they owned a small one, only that they owned one. If financial resource transfers were the dominant mechanism, by contrast, the housing size and timing of grandparental homeownership would matter greatly. Put more precisely, below we will conduct the following empirical tests. Given the rapid and exogenous change in prices of the small-size home segment of the ownership market generated by this intervention, if the norms mechanism predominated we should observe: (1) a positive impact on generation 3 housing value if a grandparent owned a dwelling instead of renting it, but (2) no significant differences over time in the impact (coefficients) of home owning grandparents based on the appreciation of dwelling owned, regardless of dwelling size. By contrast, if the financial mechanism predominated, we should observe that: (1) the impact of grandparents who owned homes with fewer than four rooms should be greater in 1990 than in 1960, because their housing sector was deregulated in the interim; and (2) the difference in impacts between grandparents who owned larger and smaller homes should shrink between 1960 and 1990 because the latter sector was deregulated in the interim, and its values should rise more quickly.

We operationalize this test by assessing the log house value for generation 3 as a function of generation 1 housing category in 1960 and 1990, restricted to paternal grandparents living in Oslo, for reasons discussed above. ${ }^{13}$ We distinguish between two housing size categories, 1-3 rooms and 5 rooms or more, which closely correspond to the regulated and non-regulated submarkets during the period 1960 to $1985 .{ }^{14}$ We specify a series of dummy variables that jointly denote grandparents' housing type and year, with renting as the omitted reference category. We employ tobit regression to estimate parameters, given the nature of the dependent variable (inclusion of renters with zero house value).

\subsection{Descriptive statistics}

Characteristics of the samples are set out in Tables 1 and 2. The interpretation of descriptive statistics for generation 1 in Oslo 1960 and 1990 (columns 5-8) and generation 3 in Norway in

\footnotetext{
${ }^{13}$ Unfortunately, we cannot include both family lines, given the sampling procedure in the 1990 census.

${ }^{14}$ Price regulations did not apply to dwellings above a certain size, which varied over time. Unfortunately, the 1960 census does not provide information about sizes of dwellings, so we resorted to number of rooms as a proxy. We have been able, however, to test the relationship between the thresholds and number of rooms using 1980 data. This shows that: (1) 90 percent of all 5 room + dwellings were above the threshold 85 percent of the time; and (2) 99 percent of all 1-3 room dwellings were below the threshold 85 percent of the time. We are thus confident that our designation of regulated and unregulated sectors using 1-3 room dwellings and 5+ room dwellings is reasonable.
} 
2014 (columns 1-4) in Table 1 are straightforward; those for generation 1 in columns 1-4 require some explanation. The data for generation 1's housing status show the mean number of generation 1 households associated with each generation 3 analysis sample household (for both the full sample and those who owned in 2014) in each of the dwelling tenure/location/size categories in 1960. Recall that both grandparental households' housing status are tallied separately for each generation 3 household in the analysis. Thus, Table 1 columns 1-4 can be interpreted from the perspective of a generation 3 household. Column 1 shows, for example, that the mean generation 3 household had only .045 grandparental households who in 1960 owned a dwelling with 1-3 rooms in Oslo, .021 who owned one there with four rooms, and .014 who owned one there with five or more rooms. Summing across the generation 1 ownership categories, we see that the mean generation 3 household had 1.32 grandparental households who in 1960 owned their dwelling somewhere in Norway. Alternatively, these figures can also be interpreted from the perspective of the average generation 1 household in 1960 by dividing the proportions shown by two. Thus, Table 1 shows that only four percent of the grandparents of the young adults we analyze owned a home in Oslo in $1960,{ }^{15}$ and were thus in a fortunate position to amass substantial housing wealth subsequently. Analogously, the data in Table 1 translates into a roughly 66 percent homeownership rate for those generation 1 households related to our generation 3 households. ${ }^{16}$ By contrast, 62 percent of our sampled young adults in generation 3 owned a home in 2014, with a mean value just above 1.9 million kroner (about $\$ 240,000$ based on an approximate $8 \mathrm{NOK}=\$ 1$ US exchange rate). Norway by 1960 had started on its drift towards homeownership, but the process was far from completed. We thus register dramatic changes for our Oslo-based generation 1 cohorts between 1960 and 1990: homeownership rates went from 46 percent to 79 percent, and the share owning large dwellings more than doubled (see columns 5 and 7 in Table 1).

Table 2 shows that our sample of generation 3 was, on average, 33 years old in 2014, had 1.9 siblings and was evenly split by gender. Sixty-three percent of this group was married or partnered, with an average of 1.3 children in the household. Their average income in 2014 was 276,000 kroner and their average (non-housing) wealth in the same year was 130,000 kroner.

\footnotetext{
15 This is derived by summing the proportions in the Oslo ownership categories (=.08) and dividing by two.

16 This is derived by summing the proportions across all the ownership categories $(=1.323)$ and dividing by two.
} 
The grandparents of generation 3 typically were born in the early 1920s and died in the late 1990s. Their average income in 1967 was 193,000 kroner (CPI-adjusted to 2014 NOK). The vast majority of grandparents resided outside of Oslo and the second-tier cities in 1960; most residing in Oslo rented. ${ }^{17}$ The parents of generation 3 typically were born in the early 1950s and the vast majority were still alive in 2014. Their average income (both parents) over 20 years since the birth of the sampled child was 360,000 kroner, their gross wealth in 1993 was 758,000 kroner (both in 2014 NOK).

\section{Results}

\subsection{Core model of grandchildren's homeownership propensity and home value}

The parameters for our core models of the probability of a grandchild owning a home in 2014 and the log value of such homes, estimated by OLS regression, are presented in Tables 3 and 4. Both tables show how the results for grandparental housing status variables change when we successively add controls for parents' and then grandchildren's income, wealth and educational attainments to the model; all models control for grandparents' income and whether they resided in the same municipality as the grandchild. Models perform acceptably according to standard goodness-of-fit criteria: adjusted R-squares are in the .15 to .18 range for both. The predominant message conveyed by Tables 3 and 4 is that there are highly statistically and substantively significant relationships between grandparents' housing status and both the probability of grandchildren owning a home and the value of the home they own, but these relationships vary dramatically according to where grandparents lived.

Consider first column (1) in Table 3, which presents the reduced-form marginal effects for the probability of owning. These estimates show the difference in the probability of owning associated with having a grandparent in the given housing status category in 1960, compared to having a grandparent who rented in a less-urbanized area. Because no mediating variables are included, the parameters in (1) can be interpreted as the "total effect" of the given grandparental housing status on the grandchild's probability of owning that is being transmitted potentially through all the causal paths portrayed in Figure 1. The pattern of coefficient magnitudes across the grandparental housing statuses is clear, consistent and dramatic: owning is greater than

\footnotetext{
${ }^{17}$ Recall that in Table 1 the generation 11960 housing status proportions sum to two since both grandparental lines are counted.
} 
renting, larger homes are greater than smaller homes, and Oslo homes are greater than in secondtier cities, which are in turn greater than in less-urbanized areas. The largest difference is exhibited for grandparents owning larger homes in Oslo in 1960: their grandchildren's probability of owning in 2014 is .055 higher, which represents an 8.9 percent increase of the mean ownership rate. Across other categories of owned homes in Oslo and in second-tier cities, the comparative benefit for grandchildren owning is in the range of .02 to .03 higher probabilities. There are no substantial differences between grandparents who owned in lessurbanized areas and those who rented in the same areas or in second-tier cities. Interestingly, having a grandparent who owned a small home in a less-urbanized area apparently imposes a slight penalty on grandchildren's likelihood of owning a home, a result we attribute to the massive loss of population and the associated housing depreciation suffered by the Norwegian countryside since 1960.

Similar qualitative conclusions can be drawn from an examination of results for grandchildren's value of home owned, presented in Table 4. Coefficients here are interpreted as the proportional increase in value associated with having a grandparent in the given housing status category in 1960, compared to having a grandparent who rented in a less-urbanized Norwegian setting. The identical hierarchy of grandparental housing status effects is exhibited, although the magnitudes are larger across the board. The value of a grandchild's home in 2014 is 28.5 percent greater if a grandparent owned a large home in Oslo in 1960; for medium-sized and smaller homes the comparable figures are 9.6 and 10.0 percent. The range of apparent impacts across the various home sizes for grandparents owning in second-tier cities is from 11.4 to 15.6 percent. As in the case of the probability of owning a home, there is no comparative benefit for grandchildren from a grandparent owning a home outside of the larger cities, perhaps even a small potential penalty if they owned a small home. There apparently is a small benefit to grandchildren's housing status if their grandparents were renters in Oslo compared to renting in less-urbanized areas; the same was true for renting in a second-tier city in the case of home value. We attribute this partly to unmeasured differences in grandparents' non-housing wealth associated with their residence in these larger urban places. Another explanation is that many urban renters were given incentives to buy their rented properties, especially in Oslo. ${ }^{18}$

\footnotetext{
${ }^{18}$ Long-term renters had the right to buy their rental apartment at a subsided price if the apartment building was converted to condominiums. Many renters in Oslo used this opportunity in the 1980s, and paid around 57 percent of
} 
In concert, the results in Tables 3 and 4 column (1) paint a powerful portrait that a grandparent's ownership of a house in a city, especially if the house is large and the city is Oslo, substantially enhances the grandchild's subsequent ability to buy a house and a more expensive one. This pattern is entirely consistent with our hypothesis that the geographically differentiated pattern of home price appreciation across Norway (that we presented earlier) has produced a coincident pattern of housing wealth increases for property owners in generation 1 , which are then transferred to generation 3 directly and indirectly.

We next consider the degree to which this intergenerational transfer occurs directly (via gifts and bequests to grandchildren) or indirectly (via shaping the income, wealth and education of parents, and/or the income and education of grandchildren). It is apparent when comparing columns (1), (2) and (3) in Tables 3 and 4 that the total effects of grandparental housing status are considerably attenuated when controls for subsequent generation's socioeconomic status are included in the models, indicating that part of the impact is transmitted through these intervening paths, as per Figure 1. Virtually all of this attenuation occurs when generation 2's income, wealth and education are controlled, suggesting that, as would be expected, generation 2's social status, not generation 3's, comprises most of the mediation.

Our structural equation models presented in Tables 5 and 6 quantify these indirect effects in a more precise way than the estimates in Tables 3 and 4, though the qualitative conclusions are the same. Table 5 presents the SEM-estimated average marginal probabilities for a grandchild owning a home associated with a grandparent in one of the housing status categories shown, instead of renting in a less-urbanized area. Note first that the estimated total effects are somewhat higher than in Table 3 but the estimates of the direct effects (i.e., total minus indirect) are virtually identical. For example, in the case of a grandparent owning a large home in Oslo, the total effect estimated by SEM is .066 instead of .055 , but the estimated direct effect is the same .023 (i.e., .066-.043 in Table 5 columns (1)-(3); cf. column (3) in Table 3).

Second, within a given geographic delineation there is a clear ordering whereby the share represented by indirect effects is positively related to the size of the total effect. For a

\footnotetext{
market price, on average. Renters in Bergen and Trondheim used the option less often. Renters were also given the option to buy renovated apartments after the public renewal in the 1980s. All this means that grandparents who were renting in Oslo in 1960 were more likely to have later become homeowners there, thereby accumulating housing wealth that could aid younger generations. Such transactions could even have taken place in generation 2 , since rental contracts could be inherited. For details, see Wessel (1996).
} 
grandparent owning a large home in Oslo, roughly two-thirds of the effect on a grandchild's probability of buying a home transpires indirectly, primarily though the impact on parent's socioeconomic status and housing status. We interpret this as evidence that, holding generation 1 income constant, greater housing wealth among these grandparents leads to improved education, income, non-housing wealth and housing wealth of parents that, in turn, assist the educational, income and non-housing wealth credentials of the next generation in ways that aid their transition into homeownership. Part of this transmission from generation 2 to generation 3 may come in the form of transfers, but we cannot observe that. By contrast, grandparents with low levels of housing wealth apparently provide some modest transfers to their grandchildren that help them into homeownership, but this form of wealth does less to help improve the socioeconomic status of the intervening generation in ways that payoff indirectly for grandchildren's housing status.

This same positive relationship between indirect effect share size of the total effect within a geographic delineation also is apparent in Table 6 when considering grandchildren's housing value, but the share that indirect effects comprise is much smaller (by roughly a half or less) than the corresponding figure in Table 5. This suggests to us that indirect effects of grandparents' housing status working through the socioeconomic status of parents and grandchildren are much more important for helping grandchildren become homeowners than it is for those who become homeowners occupying more expensive residences. For the latter outcome, it appears that direct wealth transfers across three generations are more powerful in explaining the observed relationship.

Finally, it is useful to compare the linear regression parameters presented in Tables 3 and 4 with their counterparts estimated with structural equation modeling presented in Tables 5 and 6 , respectively. The close similarity between the alternative estimates suggest that the socioeconomic statuses of parents' and grandchildren's are largely mediating factors instead of confounding factors: the additional effect from these variables that is unrelated to grandparental housing and income appears to be small.

\subsection{Test of alternative mechanisms of intergenerational transmission of housing status}

The results presented thus far imply in several ways that economic mechanisms (transfers, bequests and/or developmental context) are the predominant mechanism underlying the strong connections observed between grandparents' and grandchildren's housing status, not 
socialization of norms related to housing and homeownership. First, there is a systematic pattern of variation in impacts within the set of grandparents who owned homes in 1960: grandchildren are much more likely to own and own more expensive dwellings if their grandparents owned larger homes and/or homes in Oslo. Second, the effect of grandparent's housing status is partially mediated for both dimensions of grandchildren's housing status by the socioeconomic status of both generations 2 and 3. Third, the degree to which these relationships are mediated grows systematically as one considers grandparents who own larger homes in larger cities. All three pieces of evidence are easily explained by deducing that grandparents owning larger houses and/or houses in Oslo had (have) more housing wealth that they have transferred to their grandchildren either directly or indirectly (by shaping the socioeconomic status of their children as well as their grandchildren). It seems implausible to us that variations in housing-related norms could produce such stylized facts. Nevertheless, to gain more definitive conclusions we employ our natural experiment of price deregulation in on segment (i.e., small-size dwelling) of the owner-occupied sector in Oslo.

We compare the intergenerational transmission of housing status for two groups of grandchildren descending from grandparents who owned small and large dwellings in Oslo, at two measurement points, 1960 and 1990. Large dwellings were, as noted previously, exempt from price regulation during most of the period, whereas most small dwellings were regulated until 1982-1985. If socialization were the driving intergenerational force, we would expect the relationship between coefficients estimated for the two sets of grandchildren with different grandparent housing sizes to remain the same at both measurement points, and the coefficients within a set of grandchildren with a given grandparent housing size to remain the same over time. By contrast, if financial mechanisms were dominant we would expect a significant growth between 1960 and 1990 in the coefficient for the group whose grandparents owned smaller homes, whereas the other group ought to exhibit little difference between these measurements.

Table 7 presents the tobit model results for the value of homes owned by descendants of Oslo grandparents, which fully confirm the latter contingent expectation. Descendants of grandparents who experienced deregulation appear to have benefitted greatly from the change. The "control group" shows no significant difference, which allows a marked treatment effect to emerge. 
We thus infer that homeownership (especially of larger dwellings in more inflationary markets) generates economic resources that strongly influence individuals and families over more than two generations. ${ }^{19}$ Our data are not perfectly suited to assess the socialization thesis, of course, and we cannot reject it entirely. Nevertheless, nothing suggests that attitudes and norms could change so quickly in response to historical events occurring in Oslo during the mid1980s. Indeed, when looking at tenure preferences the most striking feature for Norway is a lack of variation. Measurements over more than 30 years have shown that (at least) 88 to 95 percent of the adult population seemingly prefers homeownership, as exhibited by their tenure choices.

\subsection{Robustness checks}

We undertake three assessments of the sensitivity of our core findings to the statistical model employed and to the measurement of grandparental housing status. Appendix A presents these robustness tests. We first consider alternative estimation methods: ordinary least-squares and logistic regression have comparative strengths and weaknesses for estimating dichotomous outcome models. Table A1. shows results from replicating the analysis in Table 3 but using logistic regression, with estimates transformed to average marginal effects, instead of a linear probability model. The same conclusions emerge as before; if anything, the point estimates for grandparental housing status variables are slightly higher in the logistic regression.

We next check to see if conclusions are sensitive to whether patrilineal and matrilineal grandparents' 1960 housing status are distinguished. Table A2. compares the estimates of the log house value model in Table 4 column (3) with the estimates for each of the two family lines, after controlling for each other. We see that most estimates remain at the same level as previously, although some minor differences appear between patrilineal and matrilineal grandparents.

Finally, we repeat the analysis of home value from Table 4 with a two-limit tobit model for the whole sample, censoring raw values at 0 and 99 percent, to assess the sensitivity of conclusions to statistical technique employed. The results (column 4 of Table A2) once again strengthens our conclusion that grandparental ownership and location produce statistically and substantively significant differences in housing values among their grandchildren. The size of the largest estimate of marginal value increase (460,000 for grandparents owning a large home in

\footnotetext{
${ }^{19}$ A corresponding emphasis on resources appears in two-generational studies from France (Spileman and Wolff,
} 2012), the United States (Aratani, 2013) and Australia (Barrett et al., 2015). 
Oslo) represents 103 percent of mean annual income for individuals between 25 and 44 years of age, measured in 2014 (Statistics Norway, 2017b).

\section{Discussion}

Our empirical investigation provides three core insights. First, there indeed appears to be a substantial grandparent effect on a young adult household's current tenure and house value in Norway, but this effect depends crucially on the degree of grandparents' urbanization. The largest intergenerational housing status transmission effects obtain when grandparents were homeowners in Oslo in 1960, with further differentiation according to the size of the dwelling. Substantially smaller advantages occur at the next scale of urbanization, i.e., when grandparents lived in a second-tier city in 1960. By contrast, it appears that grandchildren pay a penalty in their housing market opportunities if their grandparents owned a small home in the lessurbanized parts of Norway. All this implies that randomness of family history plays a non-trivial role in the housing market outcomes of the current generation; the good fortune of having a grandparent owning a large home in Oslo indeed provides a good fortune.

Second, our natural experimental evidence shows a significant treatment effect for grandchildren whose grandparents experienced price deregulation in the 1980s in Oslo. This pattern, in concert with additional evidence we have provided, strongly suggests that economic factors (bequests, transfers, and developmental context), not socialization, dominate in this intergenerational transmission process.

Third, part (but certainly not all) of the grandparental effect on grandchildren's probability of owning a home and the value of that home is mediated through its impact on the income, wealth and educational attainments of the second and, to a lesser degree, the third generations. There are three important nuances to the patterns of direct and indirect effect magnitudes we observe. First, the share of the total effect that is mediated (indirect) is larger the greater the implicit housing wealth of grandparents. Second, the typical share of statistically significant total effect that is mediated is roughly one-half in the case of grandchildren's homeownership probability, but only roughly one-fourth in the case of the value of their home. Third, the vast majority of the mediated effect in both cases comes via the influence on the parents' socioeconomic status (education, income, wealth), not on the grandchildren's socioeconomic status (compare columns 2 and 3 in Tables 5 and 6). We can first deduce from 
these facts that grandparents with greater housing status transmit some of their housing wealth directly to grandchildren in the form of gifts and/or bequests of property or monetization of that property. This provides clear support for the direct inheritances and transfers mechanism of intergenerational wealth transmission (path $\mathrm{C}$ in figure 1). We can next deduce that grandparents also use some of their housing wealth to boost the socioeconomic status of their children by financing superior developmental contexts during their childhoods and/or providing gifts during their adulthoods (paths $\mathrm{M}$ and $\mathrm{I}-\mathrm{K}$ ). These enhanced socioeconomic resources of generation 2 are, in turn, substantially conveyed to the third generation (paths $\mathrm{H}$ and $\mathrm{F}-\mathrm{B}, \mathrm{G}-\mathrm{B}$ ) ${ }^{20}$, though we cannot parse the elements of inheritance, transfers and developmental context. Some of this parental assistance helps children's housing status directly via transfers (path D), and indirectly via their enhanced socioeconomic status (path E).

Our results document the crucial role played by property wealth in perpetuating social inequalities across at least three generations. The broader point is that urbanization and housing market forces create challenges for Norway in maintaining its egalitarian social structure. Recent documentation of parallel challenges include increasing wealth at the top (Aaberge and Atkinson, 2010; Hansen 2014); increasing inequality between sectors of the economy (Wessel, 2013), increasing spatial inequalities in Oslo (Wessel, 2015; Toft and Ljunggren, 2016), and secessionist residential mobility behavior among top-income households (Galster and Magnusson Turner, 2017). The additional perspective that this study brings is that housingbased wealth transmitted across multiple generations represents a significant source of inequality due to adjustment processes within and between housing markets. A key underlying force is large-scale population movement from smaller places to larger cities, which generates highly differentiated geographies of housing price appreciation that redound to the benefit of a lucky few while tightening constraints on the unlucky many. Our study broadens and enriches the view that family property resources have in many American and Western European housing markets become increasingly important determinants of succeeding generations' opportunities for wealth accumulation and social mobility (Maclennan and Miao, 2017).

\footnotetext{
${ }^{20}$ The crucial role played by educational attainment in the intergenerational transmission of wealth also has also been identified in the U.S. (Benton and Keister, 2017) and, of course, is a longstanding tenet in the process of intergenerational transmission of socioeconomic status (Blau and Duncan, 1967).
} 
Several caveats must be noted before concluding. First, and most obviously, our results were generated for a particular epoch in Norway and they may prove considerably different in a nation with substantially different tax laws, housing market appreciation patterns, urbanization histories, social safety net systems and inter-generational cultural connections. Second, despite the unusually rich data available to us, we lack information about specific gifts and bequests, and thus our claims about transmission mechanisms must be inferential. Third, we have limited information about the housing status of grandparents besides tenure, location and number of rooms, and thus measure their housing wealth with error. Moreover, we have no measure of their non-housing wealth. Finally, we do not model the housing status of the second generation here. Future research might well flesh out this in an effort to measure more distinctly the array of causal paths hypothesized in Figure 1.

\section{Conclusions and implications}

In many fast-growing, high-priced cities it has become the norm that there is little hope for young adults getting their first foot on the homeownership ladder without "banking on mom and dad." Parents likely will have little in the "bank" to give, however, if they themselves have not purchased property that has appreciated substantially. Thus, ownership of well-located real property provides a key vehicle for transferring wealth across generations, perpetuating social and spatial inequalities thereby.

Our work shows for the first time that this process operates across at least three generations in Norway, though its power is highly contextualized by geography. The opportunities for young adults to buy homes (and more expensive ones) are substantially expanded if their grandparents owned homes (especially larger ones) in Oslo, and to a lesser degree in second-tier cities. Grandparents use their housing wealth to help their grandchildren not only directly in the form of gifts and bequests, but indirectly by augmenting the socioeconomic status and, thereby, the child developmental contexts provided by the intervening generation. The direct effects are, on average, at least as large as the indirect, mediated effects, though the share of total impact represented by indirect effects is directly related to grandparents' housing wealth. In these direct and indirect ways, property wealth serves as a core vehicle for perpetuating intergenerational inequalities in socioeconomic status. 
By implication, the rapid price inflation of housing markets currently observed in prosperous cities worldwide foreshadows the growing importance of this mechanism in the future, as homeowners in such places are able to confer increasingly large advantages on their children and grandchildren. In a more fundamental sense, our results imply that as the world urbanizes, a greater share families will be lifted "out of the middle-class mode of wealth accumulation and transmission" (Mare, 2011:8) through earnings, and instead rely on real property appreciation and the intergenerational transfer of such. 


\section{References}

Aaberge, R. and Atkinson, A.B., 2010. Top Income in Norway. In: Atkinson, A.B. and Piketty, T. (Eds.), Top Incomes: A Global Perspective. Oxford University Press, Oxford, pp. 448-481. Aaronson, D., 2000. A Note of the Benefits of Homeownership. J. Urban Econ. 47(3), 356-369. Aratani, Y., 2011. Socio-demographic variations of homeowners and differential effects of parental homeownership on offspring's housing tenure. Hous. Stud. 26(5), 723-746.

Arrondel, L. and Lefebvre, B., 2001. Consumption and investment motives in housing wealth accumulation: a French study. J. Urban Econ. 50(1), 112-137.

Barrett, G., Cigdem, M., Whelan, S. and Wood, G., 2015. The relationship between intergenerational transfers, housing and economic outcomes. Australian Housing and Urban Research Institute, Sydney.

Belsky, E. and Prakken, J., 2004. Housing Wealth Effects: Housing's Impact on Wealth Accumulation, Wealth Distribution, and Consumer Spending. Joint Center for Housing Studies of Harvard University, Cambridge, MA, Working Paper W04-13.

Benton, R. and Keister, L., 2017. The lasting effect of intergenerational wealth transfers: Human capital, family formation, and wealth. Soc. Sci. Res. 68, 1-14.

Blau, P.M. and Duncan, O.D., 1967. The American Occupational Structure. Free Press, New York.

Boehm, T.P. and Schlottmann, A.M., 2004. Wealth Accumulation and Homeownership: Evidence for Low-Income Households. US Department of Housing and Urban Development, Policy Development and Research, Washington. ., 2002. Housing and wealth accumulation: intergenerational impacts. In: Retsinas, N. and Belsky, E. (Eds.), Low-Income Homeownership: Examining the Unexamined Goal, ch. 14. Brookings Institution. Washington DC. ., 1999. Does home ownership by parents have an economic impact on their children? J. Hous. Econ. 8(3), 217-232.

Bond, S. and Eriksen, M., 2017. The Role of Parents on the Home Ownership Experience of Their Children: Evidence from the Health and Retirement Study. Available at: 
http://www.cba.uc.edu/faculty/erikseml/Papers/BondEriksen_Ownership.pdf

Brandolini, A., Cannari, L., D'Alessio, G. and Faiella, I., 2006. Household wealth in Italy in the 1990s. In: Wolff, E.N. (Ed.), International Perspectives on Household Wealth, ch7. Edward Elgar, Cheltenham, UK.

Briggs, X. deSouza, (Ed.), 1995. The Geography of Opportunity. Brookings Institution, Washington, DC.

Brooks-Gunn, J., Duncan, G. and Aber, J.L., (Eds.), 1997. Neighborhood poverty: vol. 1 Context and Consequences for Children. Russell Sage Foundation, New York.

Charles, K. and Hurst, E., 2002. The Transition to Home Ownership and the Black-White Wealth Gap. Rev. Econ. Stat. 84(2), 281-297.

Chetty, R., Hendren, N., Kline, P., Saez, E., 2014. Where is the land of opportunity? The geography of intergenerational mobility in the United States. Q. J. Econ. 129(4), 1553-1623.

Chetty, R. and Hendren, N., 2015. The Effects of Neighborhoods on Children's Long-Term Outcomes: Quasi-Experimental Estimates for the United States. Stanford University Department of Economics, Palo Alto, CA, Unpublished Working Paper.

Cox, D., 1990. Intergenerational Transfers and Liquidity Constraints. Q. J.

Econ., 105(1), 187-217.

Dietz, R. and Haurin, D., 2003. The Social and Private Micro-Level Consequences of Homeownership. J. Urban Econ. 54(3), 401-450.

Duncan, O.D., Featherman, D. and Duncan, B., 1972. Socioeconomic Background and Achievement. New York: Seminar Press.

Engelhardt, G. and Mayer, J., 1998. Intergenerational transfers, borrowing constraints, and saving behavior: evidence from the housing market. J. Urban Econ. 44(1), 135-157.

Enström Öst, C., 2012. Parental Wealth and First-time Homeownership: A Cohort Study of Family Background and Young Adults' Housing Situation in Sweden. Urban Stud. 49(10), 2137-2152. 
Flavin, M. and Yamashita, T., 2002. Owner-occupied housing and the composition of the household portfolio. Am. Econ. Rev. 92(1), 345-362.

Galster, G. and Killen, S., 1995. The geography of metropolitan opportunity: A reconnaissance and conceptual framework. Hous. Policy Debate 6(1), 7-44.

Galster, G. and Magnusson Turner, L., 2017. Status Discrepancy as a Driver of Residential Mobility: Evidence from Oslo. Environ. Plan. A. Available at: http://journals.sagepub.com/doi/abs/10.1177/0308518X17717067

Galster, G., Marcotte, D., Mandell, M., Wolman, H. and Augustine, N., 2007. The Impacts of Parental Homeownership on Children's Outcomes during Early Adulthood. Hous. Policy Debate 18(4), 785-827.

Galster, G. and Sharkey, P., 2017. Spatial foundations of inequality: An empirical overview and conceptual model. RSF 3(2), 1-34.

Green, R. and White, M., 1997. Measuring the Benefits of Homeowning: Effects on Children. J. Urban Econ. 41(3), 441-461.

Green, R., Painter, G. and White, M., 2012. Measuring the Benefits of Homeowning: Effects on Children Redux. Research Institute for Housing America, Washington, DC.

Guiso, L., and Jappelli, T., 2002. Private Transfers, Borrowing Constraints and the Timing of Homeownership. JMCB 34(2), 315-339.

Gulbrandsen, L. 1983. Boligmarked og boligpolitikk. Eksemplet Oslo [Housing market and housing policy: The Oslo case]. Oslo: Universitetsforlaget.

Gulbrandsen, L., and Langsether, A. 2003. Family transactions in the Norwegian housing market. Hous. Theory Soc. 20(3), 137-152.

Haglund, A., 2016. Modell for beregning av boligformue. Oppdatert med tall for 2015. [Model for estimation of housing wealth. Updated with numbers for 2015]. Notater 2016/07, Statistics Norway, Oslo.

Hällsten, M. and Pfeffer, F., 2017. Grand Advantage: Family Wealth and Grandchildren's Educational Achievement in Sweden. Am. Soc. Rev. 82(2), 328-360. 
Hamnett, C., Harmer, M., and Williams, P., 1991. Safe as Houses: Housing Inheritance in Britain. Paul Chapman, London.

Hansen, M., 2014. Self-Made Wealth or Family-Wealth? Changes in Intergenerational Wealth Mobility. Soc. Forces 93(2), 457-481.

Harkness, J. and Newman, S., 2002. Homeownership For the Poor in Distressed Neighborhoods: Does It Make Sense? Hous. Policy Debate 13(3), 597-630. 2003. Differential Effects of Homeownership on Children from Higher- and LowerIncome Families. J. Hous. Res. 14(1), 1-19.

Haurin, D., Parcel, T. and Haurin, R.J., 2002. Does Home Ownership Affect Child Outcomes? Real Estate Econ. 30(4), 635-666.

Haurin, R. J., 1992. Patterns of Childhood Residence and the Relationship to Young Adult Outcomes. J. Marriage Fam. 54(4), 846-880.

Haveman, R. and Wolfe, B., 1994. Succeeding Generations: On the Effects of Investments in Children. Russell Sage Foundation, New York.

Helderman, A. and Mulder, C., 2007. Intergenerational Transmission of Homeownership: the Roles of Gifts and Continuities in Housing Market Characteristics. Urban Stud. 44(2), 231-247. Henretta, J., 1984. Parental Status and Child's Home Ownership. Am. J. Sociol. 49(1), 131-140. Hilber, C. and Liu, Y., 2008. Explaining the Black-White Homeownership Gap: The Role of Own Wealth, Parental Externalities and Locational Preferences. J. Hous. Econ., 17(2), 152174.

Hodgson, L., 1992. Adult Grandchildren and their Grandparent: The Enduring Bond. Int. J. Aging Hum. 34(3), 209-225.

Jencks, C. and Mayer, S., 1990. The social consequences of growing up in a poor neighborhood. In Lynn, L. and MacGeary, M. (Eds.), Inner-City Poverty in the United States. National Academy Press, Washington, DC. 
Jencks, C., Smith, M., Acland, H., Bane, M.J., Cohen, D., Gintis, H., Heyns, B. and Michelson, S., 1972. Inequality: A Reassessment of the Effect of Family and Schooling in America. Basic Books, Washington, DC.

Jenkins, S. and Maynard, A., 1983. Intergenerational continuities in housing. Urban Stud. 20(4), 431-438.

Kenny, D.A. (2015. Measuring Model Fit. Accessed June 14, 2018. Available at http://davidakenny.net/cm/fit.htm

Kurz, K., 2004. Labor market position, intergenerational transfers and home-ownership: a longitudinal analysis for West German birth cohorts. Eur. Sociol. Rev. 20(2), 141-159.

Kurz, K. and Blossfeld, H.-P., 2004. Introduction. Social stratification, welfare regimes, and access to home ownership. In: Kurz, K. and Blossfeld, H.-P. (Eds.), Home Ownership and Social Inequality in Comparative Perspective. Stanford University Press, Palo Alto, CA, pp. 120.

Lee, H., Myers, D., Painter, G., Thunell, J., and Zissimopoulos, J., 2017. The Role of Parental Financial Assistance in the Transition to Homeownership by Young Adults. Unpublished paper, Sol Price School, University of Southern California.

Lersch, P.M. and Luijkx, R., 2015. Intergenerational transmission of homeownership in Europe: revisiting the socialization hypothesis. Soc. Sci. Res. 49, 327-342.

Lindh, T. and Ohlsson, H., 1998. Self-employment and wealth inequality. Rev. Income Wealth 44(1), 25-42.

Lindley, J. and Machin, S., 2014. Spatial changes in labor market inequality. J. Urban Econ. 79(1), 121-138.

Maclennan, D. and Miao, J., 2017. Housing and Capital in the $21^{\text {st }}$ Century. Hous. Theory Soc. 34(2), 127-145.

Mare, R., 2011. A Multigenerational View of Inequality. Demography 48(1): 1-23.

Mayer, S., 1997. What Money Can't Buy: Family Income and Children's Life Chances. Harvard University Press, Cambridge, MA. 
Mulder, C. and Smits, A., 2013. Inter-generational ties, financial transfers and home-ownership support. J. Hous. Built Env. 28(1), 95-112.

Mulder, C. and Smits, J., 1999. First-Time Home-Ownership of Couples. The Effect of InterGenerational Transmission. Eur. Sociol. Rev. 15(3), 323-337.

Mulder, C. and Wagner, M., 1998. First-time Home ownership in the Family Life Course: A West German-Dutch Comparison. Urban Stud. 35(4), 687-713.

Mulder, C., Dewilde, C., van Duijn, M. and Smits, A., 2015. The Association Between Parents' and Adult Children's Homeownership: A Comparative Analysis. Eur. J. Population 31(5): 495527.

Nordvik, V. and Åhrén, P., 2016. Bring it back. Hous. Theory Soc. 34(2): 159-166.

Norges Bank, 2017. House price indices. Available at: http://www.norges-

bank.no/en/Statistics/Historical-monetary-statistics/House-price-indices/

OECD, 2016. Social expenditure update 2016. Available at:

http://www.oecd.org/els/soc/OECD2016-Social-Expenditure-Update.pdf

Orzechowski, S. and Sepielli, P., 2003. Net worth and asset ownership of households: 1998 and 2000. Current Population Reports. US Census Bureau, Washington, DC, pp. 70-88.

Pfeffer, F.T., 2014. Multigenerational Approaches to Social Mobility. A Multifaceted Research Agenda. Res. Soc. Stratif. Mobil. 35(1), 1-12.

Poggio, T., 2008. The intergenerational transmission of home ownership and the reproduction of the familialistic welfare regime. In Saraceno, C. (Ed.), Families, ageing and social policy. Edward Elgar, Cheltenham, pp. 59-87.

Røed Larsen, E. and Weum S., 2008. Testing the efficiency of the Norwegian housing market. J. Urban Econ. 64(2), 510-517.

Rohe, W.M., van Zandt, S. and McCarthy, G., 2013. The Social Benefits and Costs of Homeownership: A Critical Review of the Research. In: Tighe, J.R. and Mueller, E.J. (Eds.), The Affordable Housing Reader. Routledge, NY, pp. 196-213.

Rothenberg, J., Galster, G.C., Butler, R.A. and Pitkin, J., 1991. The Maze of Urban Housing 
Markets: Theory, Evidence and Policy. University of Chicago Press, Chicago, IL. Scruggs, L., Jahn, D. and Kuitto, K., 2014. Comparative Welfare Entitlements Data Set 2, Version 2014-03. Accessed April 20, 2017, available at: http://cwed2.org/.

Semyonov, M. and Lewin-Epstein, N., 2001. The Impact of Parental Transfers on Living Standards of Married Children. Soc. Indic. Res. 54(2), 115-137.

Shapiro, T., Meschede, T. and Osoro, S., 2013. Widening Roots of the Racial Wealth Gap: Explaining the Black-White Economic Divide. Brandeis University, Institute on Assets and Social Policy, Waltham, MA.

Sharkey, P., 2016. Neighborhoods, Cities, and Economic Mobility. RSF 2(2), 159-177.

Smits, A. and Michielin, F., 2010. Housing values of adult children, and their parents. Is the quality of housing transmitted between generations? Hous. Stud. 25(4), 463-481.

Spilerman, S., 2004. The impact of parental wealth on early living standards in Israel. Am. J. Sociol. 110(1), 92-122.

Spilerman, S., 2000. Wealth and Stratification Processes. Annu. Rev. Sociol. 26, 497-524.

Spilerman, S. and Wolff, F-C., 2012. Parental wealth and resource transfers: How they matter in France for home ownership and living standards. Soc. Sci. Res. 41(2), 207-223

Statistics Norway, 1964. Folketelling 1960. Volum VI Boliger [Population census 1960. Volume VI Housing]. Oslo: NOS XII 157.

Statistics Norway, 2017a. Table 11035, StatBank Norway. Statistics Norway, 2017b. Table 10942, StatBank Norway.

Toft, M. and Ljunggren, J., 2016. Geographies of class advantage: The influence of adolescent neighbourhoods in Oslo. Urban Stud. 53(14), 2939-2955.

Torche, F. and Spilerman, S., 2006. Parental wealth effects on living standards and asset holdings: results from Chile. In: Wolff, E.N. (Ed.), International Perspectives on Household Wealth, ch. 10. Edward Elgar, Cheltenham, UK.

Wessel, T., 2015. Economic segregation in Oslo: polarization as a contingent outcome. In Tammaru, T., Marcinczak, S., van Ham, M. and Musterd, S. (Eds.), Socio-Economic 
Segregation in European Capital Cities. East meets West. Routledge, London and New York, pp. 95-135.

Wessel, T., 2013. Economic change and rising income inequality in the Oslo region: the importance of knowledge-intensive business services. Reg. Stud. 47(7), 1082-1094.

Wessel, T. 1996. Eierleiligheter: Framveksten av en ny boligsektor i Oslo, Bergen og Trondheim [Condominiums: the emergence of a new housing sector in Oslo, Bergen and Trondheim]. University of Oslo: Dr.philos. dissertation in political science.

Wilson, W.J., 1987. The Truly Disadvantaged: The Inner City, the Underclass, and Public Policy. University of Chicago Press, Chicago. 
Figure 1. Conceptual Framework for Intergenerational Transmission of Housing Status

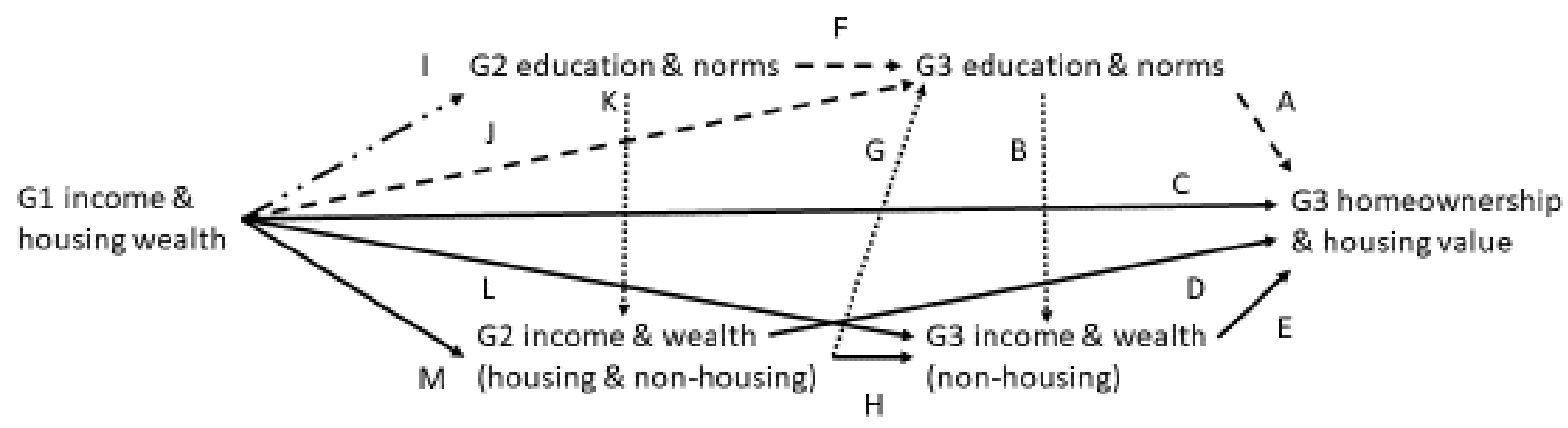

\footnotetext{
Key to causal mechanisms

inheritance and/or transfers

- - - - - socialization of norms

.................. developmental context

-... - socialization and/or developmental context
}

$\mathrm{G} 3=$ young adults; $\mathrm{G} 2=$ their parents; $\mathrm{G} 1=$ their grandparents 
Table 1

Descriptive statistics: key variables related to housing status

\begin{tabular}{|c|c|c|c|c|c|c|c|c|}
\hline & \multicolumn{2}{|c|}{ Norway: all } & \multicolumn{2}{|c|}{ Norway: owners } & \multicolumn{4}{|c|}{ Oslo $^{c}$} \\
\hline & Mean & SD & Mean & SD & Mean & SD & Mean & $\mathrm{SD}$ \\
\hline \multicolumn{9}{|l|}{ Dependent variable } \\
\hline G3 Homeownership 2014 & 0.620 & 0.485 & & & & & & \\
\hline G3 Log house value 2014 & & & 14.366 & 0.462 & & & & \\
\hline \multicolumn{9}{|l|}{ G1: housing $1960^{\mathrm{a}}$} \\
\hline Rented, rest of Norway & 0.461 & 0.623 & 0.447 & 0.615 & & & & \\
\hline Owned 1-3 rooms, rest of Norway & 0.363 & 0.562 & 0.359 & 0.560 & & & & \\
\hline Owned 4 rooms, rest of Norway & 0.285 & 0.502 & 0.289 & 0.505 & & & & \\
\hline Owned $5+$ rooms, rest of Norway & 0.444 & 0.625 & 0.449 & 0.628 & & & & \\
\hline Rented, tier- 2 city & 0.120 & 0.372 & 0.117 & 0.368 & & & & \\
\hline Owned $1-3$ rooms, tier- 2 city & 0.071 & 0.278 & 0.073 & 0.283 & & & & \\
\hline Owned 4 rooms, tier- 2 city & 0.048 & 0.227 & 0.051 & 0.233 & & & & \\
\hline Owned $5+$ rooms, tier- 2 city & 0.032 & 0.184 & 0.037 & 0.189 & & & & \\
\hline Rented, Oslo & 0.095 & 0.337 & 0.095 & 0.339 & & & & \\
\hline Owned 1-3 rooms, Oslo & 0.045 & 0.223 & 0.047 & 0.229 & & & & \\
\hline Owned 4 rooms, Oslo & 0.021 & 0.149 & 0.023 & 0.155 & & & & \\
\hline Owned $5+$ rooms, Oslo & 0.014 & 0.122 & 0.015 & 0.131 & & & & \\
\hline \multicolumn{9}{|l|}{ G1 Oslo: housing 1960/1990 b } \\
\hline Rented & & & & & 0.538 & 0.499 & 0.208 & 0.406 \\
\hline Owned 1-3 rooms & & & & & 0.258 & 0.438 & 0.394 & 0.489 \\
\hline Owned 4 rooms & & & & & 0.122 & 0.328 & 0.209 & 0.406 \\
\hline Owned $5+$ rooms & & & & & 0.081 & 0.272 & 0.189 & 0.391 \\
\hline
\end{tabular}

a The aggregate of G1 housing type proportions sums to 2, since there are two family lines coded per G3; see text for details.

b Paternal grandparents' data for Oslo used only for natural experimental analysis.

${ }^{\mathrm{c}}$ For Oslo data used only for natural experimental analysis, columns 5 and 6 relate to 1960; columns 7 and 8 to 1990 .

$\mathrm{G} 3=$ grandchildren; $\mathrm{G} 1=$ their grandparents

Columns 1-2 refer to all G3 households in analysis sample; columns 3-4 refer to 2014 G3 homeowners in analysis sample 
Table 2

Descriptive statistics: mediating and confounding variables

\begin{tabular}{|c|c|c|c|c|c|c|c|c|}
\hline & \multicolumn{2}{|c|}{ Norway: all } & \multicolumn{2}{|c|}{ Norway: owners } & \multicolumn{2}{|c|}{ Oslo $^{\mathrm{a}}$} & \multicolumn{2}{|c|}{ Oslo $^{\mathrm{b}}$} \\
\hline & Mean & SD & Mean & SD & Mean & SD & Mean & SD \\
\hline G3 in same municipality as G1 & 0.624 & 0.484 & 0.622 & 0.485 & & & & \\
\hline \multicolumn{9}{|l|}{ G1 variables: } \\
\hline Paternal grandfather: birth year & 1920.5 & 9.8 & 1919.6 & 9.5 & 1920.7 & 9.7 & 1922.5 & 9.4 \\
\hline Paternal grandmother: birth year & 1923.7 & 9.4 & 1922.8 & 9.1 & 1923.3 & 9.5 & 1923.7 & 9.3 \\
\hline Maternal grandfather: birth year & 1923.4 & 9.8 & 1922.4 & 9.5 & & & & \\
\hline Maternal grandmother: birth year & 1926.7 & 9.4 & 1925.6 & 9.1 & & & & \\
\hline Paternal grandfather: death year & 1994.0 & 12.8 & 1993.7 & 12.7 & 1994.0 & 12.8 & 1996.5 & 11.6 \\
\hline Paternal grandmother: death year & 1999.8 & 11.6 & 1999.7 & 11.5 & 1999.6 & 11.5 & 2004.1 & 7.5 \\
\hline Maternal grandfather: death year & 1995.6 & 12.7 & 1995.3 & 12.6 & & & & \\
\hline Maternal grandmother: death year & 2001.0 & 11.2 & 2000.9 & 11.1 & & & & \\
\hline Log income 1967 & 8.558 & 4.422 & 8.265 & 4.635 & 9.298 & 4.156 & 9.231 & 4.102 \\
\hline \multicolumn{9}{|l|}{ G2 variables: } \\
\hline Father: birth year & 1952.6 & 6.3 & 1951.9 & 6.0 & 1952.6 & 6.4 & 1953.6 & 6.1 \\
\hline Father: number of siblings & 2.1 & 1.6 & 2.1 & 1.6 & 1.6 & 1.3 & 1.9 & 1.5 \\
\hline Father: alive/dead (decade) & 5.8 & 0.7 & 5.8 & 0.6 & 5.8 & 0.6 & 5.8 & 0.6 \\
\hline Mother: birth year & 1955.3 & 6.1 & 1954.4 & 5.8 & 1954.9 & 6.2 & 1955.7 & 6.0 \\
\hline Mother: number of siblings & 2.3 & 1.6 & 5.9 & 0.4 & 1.6 & 1.3 & 1.8 & 1.4 \\
\hline Mother: alive/dead (decade) & 5.9 & 0.4 & 2.2 & 1.6 & 5.9 & 0.5 & 5.9 & 0.5 \\
\hline Parental education & 2.7 & 0.8 & 2.3 & 0.8 & 2.5 & 0.9 & 2.5 & 0.9 \\
\hline Log income: mean over 20 years & 12.805 & 6.501 & 12.382 & 6.835 & 13.653 & 6.071 & 13.483 & 6.054 \\
\hline Log gross wealth 1993 & 9.904 & 5.300 & 9.702 & 5.525 & 10.586 & 5.049 & 10.188 & 5.091 \\
\hline \multicolumn{9}{|l|}{ G3 variables: } \\
\hline Birth year & 1981.0 & 5.5 & 1980.1 & 5.2 & 1981.6 & 5.5 & 1982.0 & 5.3 \\
\hline Female & 0.502 & 0.500 & 0.490 & 0.500 & 0.503 & 0.500 & 0.508 & 0.500 \\
\hline Number of siblings & 1.9 & 1.2 & 1.8 & 1.1 & 1.7 & 1.1 & 1.7 & 1.1 \\
\hline Number of children & 1.3 & 1.2 & 1.4 & 1.1 & 1.1 & 1.1 & 1.0 & 1.1 \\
\hline Married/partner & 0.626 & 0.484 & 0.731 & 0.443 & 0.577 & 0.493 & 0.561 & 0.496 \\
\hline Level of education & 4.7 & 1.6 & 5.0 & 1.5 & 4.9 & 1.7 & 4.8 & 1.7 \\
\hline Student & 0.110 & 0.313 & 0.086 & 0.280 & 0.132 & 0.339 & 0.137 & 0.343 \\
\hline Log income 2014 & 10.021 & 5.136 & 9.805 & 5.427 & 9.298 & 4.156 & 10.411 & 4.774 \\
\hline Log financial wealth 2014 & 0.445 & 2.420 & 0.468 & 2.493 & 0.433 & 1.975 & 0.448 & 2.409 \\
\hline
\end{tabular}

${ }^{\mathrm{a}}$ Housing variables from 1960.

${ }^{\mathrm{b}}$ Housing variables from 1990.

G3= grandchildren; G2=their parents; G1=their grandparents; all monetary figures in 2014 NOK 


\section{Table 3}

Linear regression model of multigenerational effects on G3 homeownership probability

\begin{tabular}{|c|c|c|c|c|c|c|}
\hline \multirow[b]{2}{*}{ Grandparental housing 1960} & \multicolumn{2}{|c|}{ (1) } & \multicolumn{2}{|c|}{ (2) } & \multicolumn{2}{|c|}{ (3) } \\
\hline & Coeff. & Std.err. & Coeff. & Std.err. & Coeff. & Std.err. \\
\hline Owned 1-3 rooms, rest of Norway & $-0.004 * * *$ & 0.001 & -0.001 & 0.001 & -0.001 & 0.001 \\
\hline Owned 4 rooms, rest of Norway & $0.004 * * *$ & 0.001 & $0.004 * *$ & 0.001 & 0.002 & 0.001 \\
\hline Owned $5+$ rooms, rest of Norway & -0.000 & 0.001 & $-0.004 * * *$ & 0.001 & $-0.011 * * *$ & 0.001 \\
\hline Rented, tier- 2 city & 0.004 & 0.002 & 0.001 & 0.002 & 0.002 & 0.002 \\
\hline Owned $1-3$ rooms, tier- 2 city & $0.018 * * *$ & 0.002 & $0.014 * * *$ & 0.002 & $0.013 * * *$ & 0.002 \\
\hline Owned 4 rooms, tier- 2 city & $0.022 * * *$ & 0.003 & $0.015^{* * *}$ & 0.003 & $0.012 * * *$ & 0.003 \\
\hline Owned $5+$ rooms, tier- 2 city & $0.024 * * *$ & 0.003 & $0.012 * * *$ & 0.003 & $0.008 * * *$ & 0.003 \\
\hline Rented, Oslo & $0.008 * * *$ & 0.002 & $0.005^{*}$ & 0.002 & $0.011 * * *$ & 0.002 \\
\hline Owned 1-3 rooms, Oslo & $0.022 * * *$ & 0.003 & $0.014 * * *$ & 0.003 & $0.018 * * *$ & 0.003 \\
\hline Owned 4 rooms, Oslo & $0.029 * * *$ & 0.004 & $0.013 * * *$ & 0.004 & $0.015 * * *$ & 0.004 \\
\hline Owned $5+$ rooms, Oslo & $0.055 * * *$ & 0.005 & $0.023 * * *$ & 0.005 & $0.023 * * *$ & 0.005 \\
\hline G3 in same municipality as G1 control & Yes & & Yes & & Yes & \\
\hline G1 income control & Yes & & Yes & & Yes & \\
\hline G1, G2 and G3 demographic controls & Yes & & Yes & & Yes & \\
\hline G2 SES controls & & & Yes & & Yes & \\
\hline G3 SES controls & & & & & Yes & \\
\hline Adjusted $\mathrm{R}^{2}$ & 0.118 & & 0.128 & & 0.153 & \\
\hline Individuals & 661,798 & & 661,798 & & 661,798 & \\
\hline
\end{tabular}

$* \mathrm{p}<0.05$.

$* * \mathrm{p}<0.01$.

$* * * \mathrm{p}<0.001$.

$\mathrm{G} 3=$ grandchildren; $\mathrm{G} 2=$ their parents; $\mathrm{G} 1=$ their grandparents 


\section{Table 4}

Linear regression model of multigenerational effects on G3 log house value; G3 homeowners only

\begin{tabular}{|c|c|c|c|c|c|c|}
\hline \multirow[b]{2}{*}{ Grandparental housing 1960} & \multicolumn{2}{|c|}{ (1) } & \multicolumn{2}{|c|}{ (2) } & \multicolumn{2}{|c|}{ (3) } \\
\hline & Coeff. & Std.err. & Coeff. & Std.err. & Coeff. & Std.err. \\
\hline Owned 1-3 rooms, rest of Norway & $-0.020 * * *$ & 0.002 & -0.013 & 0.001 & $-0.013 * * *$ & 0.001 \\
\hline Owned 4 rooms, rest of Norway & 0.000 & 0.002 & 0.002 & 0.002 & 0.000 & 0.002 \\
\hline Owned $5+$ rooms, rest of Norway & $0.025 * * *$ & 0.001 & $0.023 * * *$ & 0.001 & $0.017 * * *$ & 0.001 \\
\hline Rented, tier-2 city & $0.109 * * *$ & 0.002 & $0.105^{* * *}$ & 0.002 & $0.104 * * *$ & 0.002 \\
\hline Owned $1-3$ rooms, tier-2 city & $0.114 * * *$ & 0.003 & $0.108 * * *$ & 0.003 & $0.106 * * *$ & 0.002 \\
\hline Owned 4 rooms, tier- 2 city & $0.129 * * *$ & 0.003 & $0.118 * * *$ & 0.003 & $0.114 * * *$ & 0.003 \\
\hline Owned $5+$ rooms, tier- 2 city & $0.156^{* * * *}$ & 0.004 & $0.136 * * *$ & 0.004 & $0.124 * * *$ & 0.004 \\
\hline Rented, Oslo & $0.087 * * *$ & 0.002 & $0.082 * * *$ & 0.002 & $0.084 * * *$ & 0.002 \\
\hline Owned 1-3 rooms, Oslo & $0.096 * * *$ & 0.003 & $0.085^{* * *}$ & 0.003 & $0.085 * * *$ & 0.003 \\
\hline Owned 4 rooms, Oslo & $0.150 * * *$ & 0.004 & $0.121 * * *$ & 0.004 & $0.116 * * *$ & 0.004 \\
\hline Owned $5+$ rooms, Oslo & $0.285 * * *$ & 0.005 & $0.230 * * *$ & 0.005 & $0.203 * * *$ & 0.005 \\
\hline G3 in same municipality as G1 control & Yes & & Yes & & Yes & \\
\hline G1 income control & Yes & & Yes & & Yes & \\
\hline G1, G2 and G3 demographic controls & Yes & & Yes & & Yes & \\
\hline G2 SES controls & & & Yes & & Yes & \\
\hline G3 SES controls & & & & & Yes & \\
\hline Adjusted $\mathrm{R}^{2}$ & 0.129 & & 0.157 & & 0.184 & \\
\hline Individuals & 410,453 & & 410,453 & & 410,453 & \\
\hline
\end{tabular}

$* \mathrm{p}<0.05$.

$* * \mathrm{p}<0.01$.

$* * * \mathrm{p}<0.001$.

$\mathrm{G} 3=$ grandchildren; $\mathrm{G} 2=$ their parents; $\mathrm{G} 1=$ their grandparents 


\section{Table 5}

Structural equation model of multigenerational effects on G3 homeownership probability, with G2 and G3 SES as mediating variables; Linear probability model

\begin{tabular}{|c|c|c|c|c|c|c|c|}
\hline \multirow[b]{3}{*}{ G1 housing 1960} & \multicolumn{2}{|c|}{ Total effects } & \multicolumn{4}{|c|}{ Indirect effects } & \multirow{3}{*}{$\begin{array}{c}\% \\
\text { indirect }\end{array}$} \\
\hline & \multicolumn{2}{|l|}{ (1) } & \multicolumn{2}{|c|}{$\begin{array}{l}\text { Via G2 SES } \\
\text { (2) }\end{array}$} & \multicolumn{2}{|c|}{$\begin{array}{c}\text { Via G2 \& G3 SES } \\
\text { (3) }\end{array}$} & \\
\hline & Coeff. & Std.err. & Coeff. & Std.err. & Coeff. & Std.err. & \\
\hline Owned 1-3 rooms, rest of Norway & $-0.004 * * *$ & 0.001 & $-0.003 * * *$ & 0.000 & $-0.002 * * *$ & 0.000 & 46.2 \\
\hline Owned 4 rooms, rest of Norway & $0.006^{* * *}$ & 0.001 & $0.001 * * *$ & 0.000 & $0.005 * * *$ & 0.000 & 86.2 \\
\hline Owned $5+$ rooms, rest of Norway & 0.001 & 0.001 & $0.004 * * *$ & 0.000 & $0.012 * * *$ & 0.000 & 852.6 \\
\hline Rented, tier- 2 city & 0.001 & 0.002 & $0.001 * * *$ & 0.000 & 0.000 & 0.000 & 25.4 \\
\hline Owned $1-3$ rooms, tier- 2 city & $0.019 * * *$ & 0.002 & $0.004 * * *$ & 0.000 & $0.007 * * *$ & 0.001 & 38.4 \\
\hline Owned 4 rooms, tier- 2 city & $0.024 * * *$ & 0.003 & $0.008 * * *$ & 0.000 & $0.013 * * *$ & 0.001 & 53.0 \\
\hline Owned $5+$ rooms, tier- 2 city & $0.027 * * *$ & 0.003 & $0.013 * * *$ & 0.000 & $0.020 * * *$ & 0.001 & 73.2 \\
\hline Rented, Oslo & $0.013 * * *$ & 0.002 & $0.005 * * *$ & 0.000 & $0.002 * * *$ & 0.000 & 16.4 \\
\hline Owned 1-3 rooms, Oslo & $0.030 * * *$ & 0.003 & $0.011 * * *$ & 0.000 & $0.012 * * *$ & 0.001 & 39.9 \\
\hline Owned 4 rooms, Oslo & $0.038 * * *$ & 0.004 & $0.022 * * *$ & 0.001 & $0.024 * * *$ & 0.001 & 64.1 \\
\hline Owned $5+$ rooms, Oslo & $0.066^{* * *}$ & 0.005 & $0.039 * * *$ & 0.001 & $0.043 * * *$ & 0.001 & 65.6 \\
\hline$\overline{\mathrm{AIC}}$ & \multicolumn{2}{|c|}{$-2.213 e+8$} & \multicolumn{2}{|c|}{$-1.938 \mathrm{e}+8$} & \multicolumn{2}{|c|}{$-1.847 e+8$} & \\
\hline Individuals & \multicolumn{2}{|c|}{661,798} & \multicolumn{2}{|c|}{661,798} & \multicolumn{2}{|c|}{661,798} & \\
\hline
\end{tabular}

Note: Model Controls for G1 demographics and SES, G2 demographics, G3 demographics, and spatial proximity between G1 1 and G3.

$* \mathrm{p}<0.05$.

$* * \mathrm{p}<0.01$

$* * * \mathrm{p}<0.001$.

$\mathrm{G} 3=$ grandchildren; $\mathrm{G} 2=$ their parents; $\mathrm{G} 1=$ their grandparents 


\section{Table 6}

Structural equation model of multigenerational effects on G3 log house value, with G2 and G3 SES as mediating variables; G3 homeowners only.

\begin{tabular}{|c|c|c|c|c|c|c|c|}
\hline \multirow[b]{4}{*}{ G1 housing 1960} & \multicolumn{2}{|c|}{ Total effects } & \multicolumn{4}{|c|}{ Indirect effects } & \multirow{3}{*}{$\begin{array}{c}\% \\
\text { indirect }\end{array}$} \\
\hline & \multirow{2}{*}{\multicolumn{2}{|c|}{ (1) }} & \multicolumn{2}{|c|}{ Via G2 SES } & \multirow{2}{*}{\multicolumn{2}{|c|}{$\begin{array}{c}\text { Via G2 \& G3 SES } \\
\text { (3) }\end{array}$}} & \\
\hline & & & (2) & & & & \\
\hline & Coeff. & Std.err. & Coeff. & Std.err. & Coeff. & Std.err. & \\
\hline Owned 1-3 rooms, rest of Norway & $-0.020 * * *$ & 0.002 & $-0.008 * * *$ & 0.000 & $-0.007 * * *$ & 0.000 & 33.4 \\
\hline Owned 4 rooms, rest of Norway & 0.003 & 0.016 & $-0.000 * * *$ & 0.000 & $0.003 * * *$ & 0.000 & 120.8 \\
\hline Owned $5+$ rooms, rest of Norway & $0.028 * * *$ & 0.014 & $0.004 * * *$ & 0.000 & $0.012 * * *$ & 0.000 & 42.2 \\
\hline Rented, tier-2 city & $0.109 * * *$ & 0.020 & $0.003 * * *$ & 0.001 & $0.004 * * *$ & 0.001 & 3.7 \\
\hline Owned $1-3$ rooms, tier- 2 city & $0.118 * * *$ & 0.026 & $0.010 * * *$ & 0.001 & $0.013 * * *$ & 0.001 & 11.4 \\
\hline Owned 4 rooms, tier- 2 city & $0.135 * * *$ & 0.030 & $0.0016^{* * *}$ & 0.001 & $0.022 * * *$ & 0.001 & 16.7 \\
\hline Owned $5+$ rooms, tier- 2 city & $0.162 * * *$ & 0.037 & $0.025 * * *$ & 0.001 & $0.039 * * *$ & 0.001 & 24.0 \\
\hline Rented, Oslo & $0.097 * * *$ & 0.022 & $0.010 * * *$ & 0.000 & 0.011 & 0.001 & 11.0 \\
\hline Owned 1-3 rooms, Oslo & $0.110 * * *$ & 0.031 & $0.020 * * *$ & 0.001 & $0.024 * * *$ & 0.001 & 21.9 \\
\hline Owned 4 rooms, Oslo & $0.166 * * *$ & 0.045 & $0.038 * * *$ & 0.001 & $0.045 * *$ & 0.000 & 28.6 \\
\hline Owned $5+$ rooms, Oslo & $0.307 * * *$ & 0.053 & $0.062 * * *$ & 0.001 & $0.096^{* * *}$ & 0.002 & 31.2 \\
\hline$\overline{\mathrm{AIC}}$ & -2.18 & & 1.91 & & -1.8 & & \\
\hline Individuals & 410, & & 410,4 & & 41 & & \\
\hline
\end{tabular}

Note: Models control for G1 demographics and SES, G2 demographics, G3 demographics, and spatial proximity between G1 1 and G3.

$* \mathrm{p}<0.05$.

$* * p<0.01$.

$* * * \mathrm{p}<0.001$.

$\mathrm{G} 3=$ grandchildren; $\mathrm{G} 2=$ their parents; $\mathrm{G} 1=$ their grandparents 


\section{Table 7}

Tobit model of paternal grandparents' housing status on G3 log house value 1960 and 1990, Oslo (reference category: G1 rented dwelling in Oslo)

\begin{tabular}{lrrrrr}
\hline Grandparental housing 1960 & 1960 & & \multicolumn{2}{c}{ Diff. 1960/1990 } \\
\hline & Coeff. & Std.err. & Coeff. & Std.err. \\
\hline Owned 1-3 rooms & $0.091^{*}$ & 0.045 & $0.348^{* * *}$ & 0.105 & $0.257^{*}$ \\
Owned 5 + rooms & $0.251^{* * *}$ & 0.063 & 0.221 & 0.120 & -0.030 \\
Diff. 1-3 rooms and 5 + rooms & $-0,160^{*}$ & 0.049 & 0.127 & 0.110 & $0.287^{*}$ \\
\hline Individuals & 57,606 & & 13,960 &
\end{tabular}

Note: Models control for paternal G1 demographics and SES, G2 demographics and SES, and G3 demographics and SES.

$* \mathrm{p}<0.05$.

$* * \mathrm{p}<0.01$

$* * * \mathrm{p}<0.001$.

$\mathrm{G} 3=$ grandchildren; $\mathrm{G} 2=$ their parents; $\mathrm{G} 1=$ their grandparents 


\section{Appendix Table A1.}

Logistic regression model of multigenerational effects on G3 homeownership. Average marginal effects

\begin{tabular}{|c|c|c|c|c|c|c|}
\hline \multirow[b]{2}{*}{ Grandparental housing 1960} & \multicolumn{2}{|c|}{ (1) } & \multicolumn{2}{|c|}{ (2) } & \multicolumn{2}{|c|}{ (3) } \\
\hline & Coeff. & Std.err. & Coeff. & Std.err. & Coeff. & Std.err. \\
\hline Owned 1-3 rooms, rest of Norway & $-0.005 * * *$ & 0.001 & -0.002 & 0.001 & $-0.002 * * *$ & 0.001 \\
\hline Owned 4 rooms, rest of Norway & $0.003 *$ & 0.001 & $0.003 * *$ & 0.001 & 0.001 & 0.001 \\
\hline Owned $5+$ rooms, rest of Norway & -0.002 & 0.001 & $-0.004 * * *$ & 0.001 & $-0.010 * * *$ & 0.001 \\
\hline Rented, tier-2 city & 0.002 & 0.002 & 0.001 & 0.002 & 0.001 & 0.002 \\
\hline Owned $1-3$ rooms, tier-2 city & $0.018 * * *$ & 0.002 & $0.014 * * *$ & 0.002 & $0.013 * * *$ & 0.002 \\
\hline Owned 4 rooms, tier- 2 city & $0.022 * * *$ & 0.003 & $0.016^{* * *}$ & 0.003 & $0.013 * * *$ & 0.003 \\
\hline Owned $5+$ rooms, tier- 2 city & $0.024 * * *$ & 0.003 & $0.013 * * *$ & 0.003 & $0.009 * * *$ & 0.003 \\
\hline Rented, Oslo & $0.008 * * *$ & 0.002 & $0.009 * * *$ & 0.002 & $0.011 * * *$ & 0.002 \\
\hline Owned 1-3 rooms, Oslo & $0.022 * * *$ & 0.003 & $0.016 * * *$ & 0.003 & $0.019 * * *$ & 0.003 \\
\hline Owned 4 rooms, Oslo & $0.030 * * *$ & 0.004 & $0.015^{* * *}$ & 0.004 & $0.017 * * *$ & 0.004 \\
\hline Owned 5 + rooms, Oslo & $0.059 * * *$ & 0.005 & $0.031 * * *$ & 0.005 & $0.032 * * *$ & 0.005 \\
\hline G3 in same municipality as G1 control & Yes & & Yes & & Yes & \\
\hline G1 income control & Yes & & Yes & & Yes & \\
\hline G1, G2 and G3 demographic controls & Yes & & Yes & & Yes & \\
\hline G2 SES controls & & & Yes & & Yes & \\
\hline G3 SES controls & & & & & Yes & \\
\hline Log likelihood & $-399,184$ & & $-395,288$ & & $-386,021$ & \\
\hline Individuals & 661,798 & & 661,798 & & 661,798 & \\
\hline
\end{tabular}

$* \mathrm{p}<0.05$.

$* * \mathrm{p}<0.01$.

$* * * \mathrm{p}<0.001$.

G3= grandchildren; G2=their parents; G1=their grandparents 


\section{Appendix Table A2.}

Alternative estimations of log house value

\begin{tabular}{lrrrr}
\hline & \multicolumn{4}{c}{ Alternative estimations of log house value } \\
\cline { 2 - 4 } Grandparental housing 1960 & $(1)$ & $(2)$ & $(3)$ & $(4)$ \\
\hline Owned 1-3 rooms, rest of Norway & Table 4, col. 3 & Paternal G1 & Maternal G1 & Two-limit tobit \\
Owned 4 rooms, rest of Norway & $-0.013^{* * *}$ & $-0.013^{* * *}$ & $-0.013^{* * *}$ & $-24^{* * *}$ \\
Owned 5 + rooms, rest of Norway & 0.000 & -0.001 & 0.001 & 3 \\
Rented, tier-2 city & $0.017^{* * *}$ & $0.019^{* * *}$ & $0.015^{* * *}$ & $-9 *$ \\
Owned 1-3 rooms, tier-2 city & $0.104^{* * *}$ & $0.108^{* * *}$ & $0.101^{* * *}$ & $129 * * *$ \\
Owned 4 rooms, tier-2 city & $0.106^{* * *}$ & $0.109^{* * *}$ & $0.103^{* * *}$ & $177^{* * *}$ \\
Owned 5 + rooms, tier-2 city & $0.114^{* * *}$ & $0.118^{* * *}$ & $0.109^{* * *}$ & $190^{* * *}$ \\
Rented, Oslo & $0.124^{* * *}$ & $0.134^{* * *}$ & $0.114^{* * *}$ & $207^{* * *}$ \\
Owned 1-3 rooms, Oslo & $0.084^{* * *}$ & $0.088^{* * *}$ & $0.081^{* * *}$ & $152^{* * * *}$ \\
Owned 4 rooms, Oslo & $0.085^{* * *}$ & $0.093^{* * *}$ & $0.078^{* * *}$ & $180^{* * * *}$ \\
Owned 5 + rooms, Oslo & $0.116^{* * *}$ & $0.122^{* * *}$ & $0.109^{* * *}$ & $231^{* * *}$ \\
\hline Individuals & $0.203^{* * *}$ & $0.228^{* * *}$ & $0.176^{* * *}$ & $464 * * *$ \\
\hline
\end{tabular}

Note: Models control for G1 demographics and SES, G2 demographics and SES, G3 demographics and SES, and spatial proximity between G1 1 and G3. Column (2) controls for maternal G1. Column (3) controls for paternal G1. All models include all controls listed in Table 3. Column (4): 1000 NOK.

$* \mathrm{p}<0.05$.

$* * \mathrm{p}<0.01$

$* * * \mathrm{p}<0.001$

$\mathrm{G} 3=$ grandchildren; $\mathrm{G} 2=$ their parents; $\mathrm{G} 1=$ their grandparents 